NIST Technical Note 1831

\title{
Detecting Faults in Building Air Handling Units - A Background Study for Developing Intelligent Agents for Optimizing Building HVAC Systems
}

George E. Kelly

Steven T. Bushby 
NIST Technical Note 1831

\section{Detecting Faults in Building Air Handling Units - A Background Study for Developing Intelligent Agents for Optimizing Building HVAC Systems}

George E. Kelly

Steven T. Bushby

Energy and Environment Division

Engineering Laboratory

http://dx.doi.org/10.6028/NIST.TN.1831

April 2014

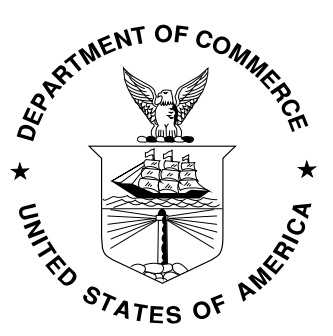

U.S. Department of Commerce Penny Pritzker, Secretary

National Institute of Standards and Technology Patrick D. Gallagher, Under Secretary of Commerce for Standards and Technology and Director 
Certain commercial entities, equipment, or materials may be identified in this document in order to describe an experimental procedure or concept adequately. Such identification is not intended to imply recommendation or endorsement by the National Institute of Standards and Technology, nor is it intended to imply that the entities, materials, or equipment are necessarily the best available for the purpose.

National Institute of Standards and Technology Technical Note 1831

Natl. Inst. Stand. Technol. Tech. Note 1831, 39 pages (April 2014)

http://dx.doi.org/10.6028/NIST.TN.1831

CODEN: NTNOEF 


\section{Contents}

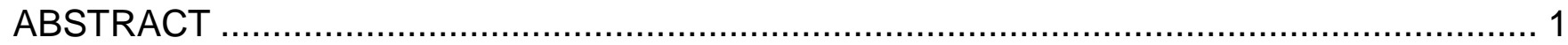

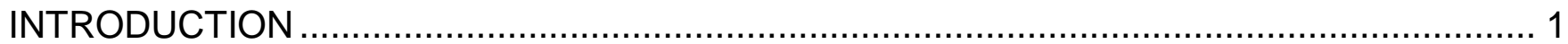

FAULT DETECTION BASED ON A SIMPLE MIXING BOX MODEL $\ldots \ldots \ldots \ldots \ldots \ldots \ldots \ldots \ldots \ldots \ldots \ldots$

FAULT DETECTION BASED ON A SIMPLE COOLING COIL MODEL ............................... 11

MIXING BOX FAULT DETECTION RESULTS........................................................................................................22

COOLING COIL FAULT DETECTION RESULTS.........................................................................................................25

DETECTION OF FAULT IN CHILLED WATER TEMPERATURE SENSOR …………………………………………......26

DETECTION OF FAULT IN SUPPLY AIR TEMPERATURE SENSOR ……………………………………………….....2

FAULT IN ENTERING AIR TEMPERATURE SENSOR …………………………………………………………..2

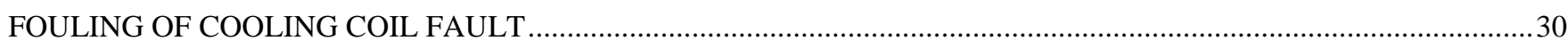

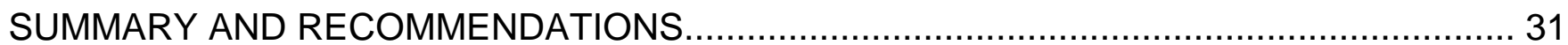

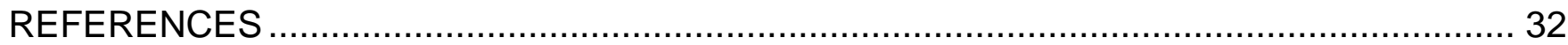

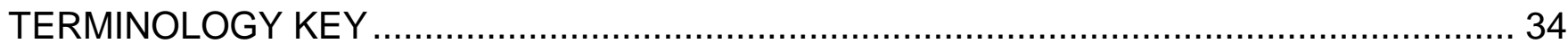




\section{ABSTRACT}

One approach to the optimization of building heating, ventilation and air-conditioning (HVAC) systems involves the use of intelligent agents. These Agents can be used for minimizing energy consumption, maximizing occupant comfort, fault detection, performing diagnostics, and improving system commissioning. This paper lays the ground work for using intelligent agents for fault detection in HVAC applications involving air handling units (AHUs). Specifically, it looks at which faults in AHU mixing boxes and cooling coils can be detected and under what conditions. Such an understanding is necessary before intelligent agents can be developed, tested, and implemented in real building HVAC systems. A simple mixing box model (Tan 2006) and a simple cooling coil model (Wang 2004) are used to represent the performance of a typical AHU, and system identification is performed using piece-wise linear approximations. Questions addressed include which variables should be used in the identification process, how many linear segments should be used for each variable, how large a fault must be in order to be detected given the inherent inaccuracies in the piece-wise linear approximation process, and over what range of external variables (e.g., environmental conditions) is fault detection possible.

\section{INTRODUCTION}

Intelligent agents know or can learn the performance and status of the systems and equipment they monitor and can communicate and collaborate with other agents to achieve a common goal. In a previous investigation (Kelly 2011) (Kelly 2012), a simulation test bed was developed and used to study how agents can learn and interact to minimize energy consumption. This learning process, called “system identification” (Ljung 1987), makes intelligent agents ideally suited for detecting and identifying faults in building HVAC systems.

Since the proper operation of building systems is important for occupant safety and comfort and for minimizing operating and maintenance costs, the detection and diagnosing of operating faults in real time is an essential part of ensuring that building systems operate properly. Fault detection and diagnosis (FDD) methods have been employed in many applications, but their implementation in real building systems has lagged. In the period 1991 through 2001 considerable work on the development and implementation of FDD methods for building HVAC equipment and systems was carried out by researchers from a number of countries working together in two research projects sponsored by the International Energy Agency (IEA). These were IEA Annex 25, which focused on the energy performance diagnosis of building and HVAC systems and the fault detection of HVAC components and sub processes, and Annex 34, which involved working with control manufacturers, industrial partners, and building owners and operators to demonstrate the benefits of computer aided fault detection and diagnostic systems in real building applications.

The IEA Annex 25 Building Optimization and Fault Diagnosis Source Book (Hyvärinen 1996) contains a detailed list of possible building HVAC faults, including typical faults for variable air volume (VAV) air handling units (AHUs). It also discusses in great detail a variety of FDD methods, such as the use of physical and black box models, state and parameter estimation, the use of artificial neural networks and expert systems, and fuzzy model-based approaches. A more recent review of research in this area can be found in two review articles by Katipamula and Brambley (Katipamula 2005 Parts I and II). One of the more promising methods for detecting faults in AHUs is called APAR, which stands for "Air Handling 
Unit Performance Assessment Rules” (Schein 2006). It uses a set of expert rules derived from mass and energy balances to detect faults. A two stage method for the detection and diagnoses of faults in a variety of HVAC subsystems (including heat exchangers) in the presence of sensor faults is described in a paper by Wang, Zhou, and Xiao (Wang 2010). It uses a sensor fault detection, diagnosis and estimation (FDD\&E) method to evaluate the health of sensor measurements and recover faulty sensor readings. System level faults (e.g., heat exchanger fouling) are then detected and diagnosed using performance indices (PIs) (e.g., the coil heat transfer coefficient) chosen to evaluate the performance of each HVAC subsystem. This reference paper also gives a good summary of recent research on FDD in building HVAC applications.

This paper lays the ground work for using intelligent agents for fault detection in HVAC applications by examining the detection of a limited number of faults in a typical VAV AHU, a schematic of which is shown in Figure 1. Mixing box faults and cooling coil faults that are normally masked by the operation of closed loop controllers are considered. For the mixing box these include stuck recirculation, inlet, and exhaust dampers, and for the cooling coil they include faults in the chilled water, supply air, and entering air temperature sensors and cooling coil fouling. These are the most difficult types of faults to detect because the closed loop controllers normally act to compensate for the fault and the controlled variable (in this case the supply air temperature) remains unaffected.

The paper examines which of the above faults can be detected and under what conditions. A simple mixing box model (Tan 2006) and a simple cooling coil model (Wang 2004) are used to represent the performance of a typical mixing box and cooling coil in a VAV AHU. Since the purpose of this work was to explore how intelligent agents could be used for fault detection in real HVAC applications, system identification is performed using results from the simple mixing box and cooling coil models. Piece-wise linear approximations are employed to simulate the use of piece-wise linear regression by building intelligent agents for system identification. 


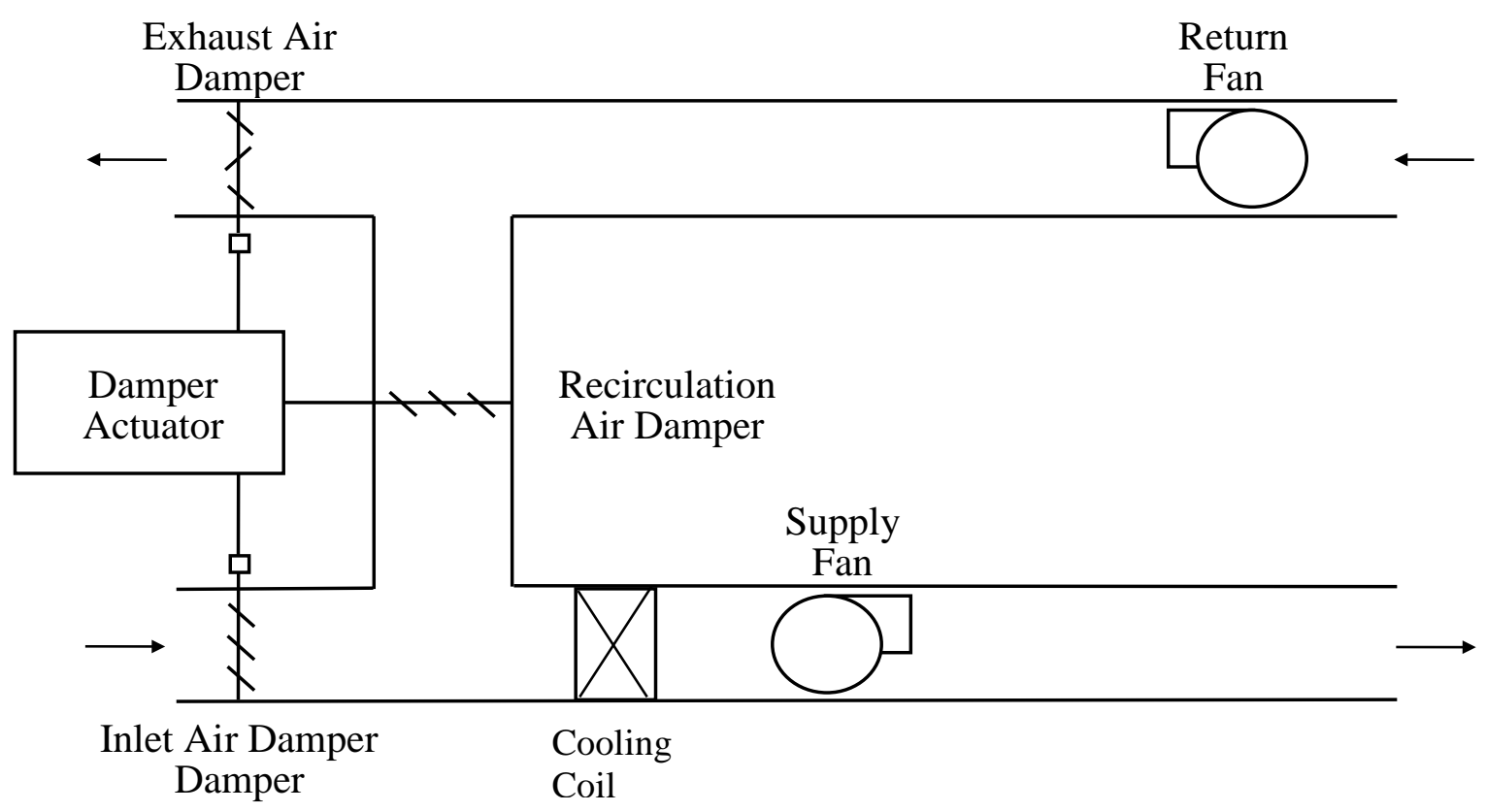

Figure 1. A typical variable air volume air handling unit

The models developed by the system identification process are used to represent the performance of the mixing box and cooling coil when no faults are present. When a fault is present, the closed loop controllers act to maintain the supply air temperature setpoint by adjusting the control signal to the mixing box dampers or adjusting the position of the valve controlling the water flow through the cooling coil. When this mixing box damper control signal or cooling coil valve position is inserted in the nofault models developed through system identification, it results in a predicted supply air temperature different from the supply air temperature setpoint. The difference or residual between this predicted supply air temperature and the supply air temperature setpoint can be used to detect the presence of a fault. However, errors introduced in the system identification can also cause errors between the predicted supply air temperature and the supply air temperature setpoint even when no faults are present. These errors, that result from the system identification process, determine how large a fault must be before it can be recognized as an actual fault.

The research in this paper looks at which AHU variables should be used in the identification process and how many linear segments should be used for each variable. It then addresses how large a mixing box or cooling coil fault must be in order to be detected given the inherent inaccuracies in the piece-wise linear approximation process, and over what range of external variables (e.g. environmental conditions) is fault detection possible for each fault. Recommendations are also made on future research needed for the development of intelligent agents capable of performing fault detection in real building AHUs. 


\section{FAULT DETECTION BASED ON A SIMPLE MIXING BOX MODEL}

A schematic of a typical mixing box found in building AHUs is shown in Figure 2.

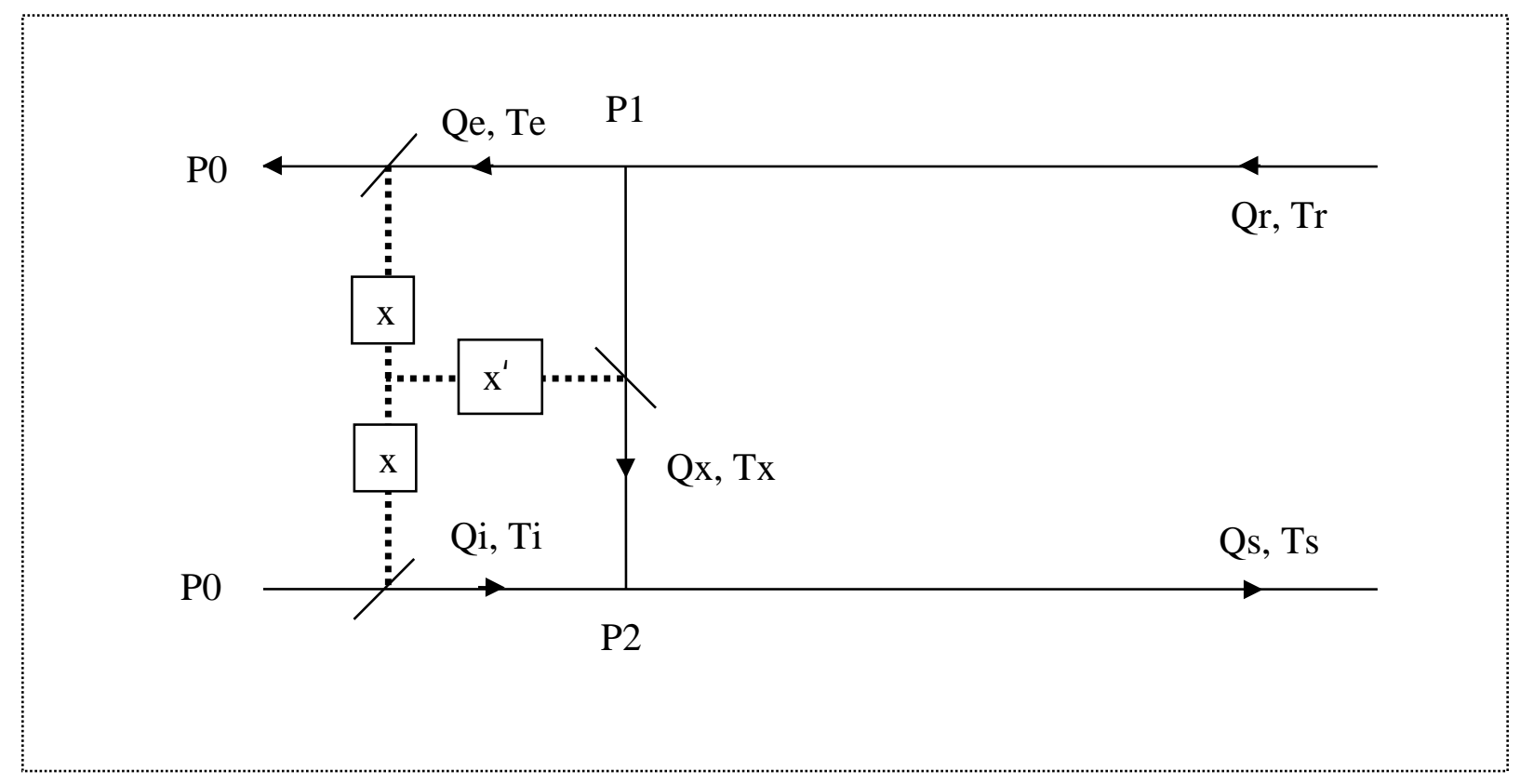

Figure 2. Schematic of a typical AHU mixing box.

The variable $\mathrm{x}$ is the control signal to the inlet air and exhaust air dampers and corresponds to the position of the dampers ( $\mathrm{x}$ ranges from $0=$ closed to $1=$ open) and $\mathrm{x}^{\prime}=(1-\mathrm{x})$ is the control signal to the recirculation air damper and corresponds to the position of the damper $(0=$ closed, $1=$ open $)$ and

$\mathrm{P} 0$ is the atmospheric pressure

$\mathrm{P} 1(\mathrm{x})$ is the pressure at the junction of the return air duct and recirculating air duct

$\mathrm{P} 2(\mathrm{x})$ is pressure at the junction of the recirculating air duct and the supply air duct

Qs is the supply air flow rate

Qr is the return air flow rate

$\mathrm{Qe}(\mathrm{x})$ is the exhaust air flow rate

$\mathrm{Qx}(\mathrm{x})$ is the recirculating air flow rate

$\mathrm{Qi}(\mathrm{x})$ is the inlet air flow rate

$\operatorname{Tx}(\mathrm{x})$ is the temperature of the recirculating air

$\mathrm{Ts}(\mathrm{x})$ is the temperature of the supply air

Te is the temperature of the exhaust air

Tr is the temperature of the Return Air

$\mathrm{Ti}$ is the temperature of the Inlet Air

It will be assumed that there is no Mixed Air Temperature sensor present and the dampers are being modulated to maintain the supply air temperature, Ts(x), at a specific setpoint. This is consistent with a 
typical Dry Bulb Economizer Cycle where modulation of the dampers occurs only after the cooling coil valve is completely closed. It is also assumed that the air streams are fully mixed so that a single temperature characterizes the air properties.

Performing mass and an energy balances and assuming $\mathrm{Tx}=\mathrm{Tr}$ and $\mathrm{Te}=\mathrm{Tr}$, one finds that:

$\mathrm{Qi}(\mathrm{x})=\mathrm{Qs}-\mathrm{Qx}(\mathrm{x})$

$\mathrm{Qe}(\mathrm{x})=\mathrm{Qr}-\mathrm{Qx}(\mathrm{x})$

$\mathrm{Qs} \cdot \operatorname{Ts}(\mathrm{x})=\mathrm{Qx}(\mathrm{x}) \cdot \operatorname{Tr}+\mathrm{Qi}(\mathrm{x}) \cdot \mathrm{Ti}$

These three equations can be rearranged to give:

$\mathrm{Qx}(\mathrm{x}) / \mathrm{Qs}=(\operatorname{Ts}(\mathrm{x})-\mathrm{Ti}) /(\mathrm{Tr}-\mathrm{Ti})$

$\mathrm{Qi}(\mathrm{x}) / \mathrm{Qs}=1-\mathrm{Qx}(\mathrm{x}) / \mathrm{Qs}$

$\mathrm{Qe}(\mathrm{x}) / \mathrm{Qs}=\mathrm{Qr} / \mathrm{Qs}-\mathrm{Qx}(\mathrm{x}) / \mathrm{Qs}$

An intelligent agent might perform system identification by dividing $\mathrm{x}$ in to several different connected regions, observe the operation of the mixing box over time, and record $\mathrm{x}$ and the calculated value of Qx(x)/Qs as given by the above equation. With closed loop control, Ts(x) should be equal to the supply air temperature setpoint, but $\mathrm{x}$ (which depends on the characteristics of the dampers) will vary with changes in Tr and Ti. Linear regression could then be performed in each region to determine $\mathrm{Qx}(\mathrm{x}) / \mathrm{Qs}$ as a function of $\mathrm{x}$.

An alternative method might involve varying $\mathrm{x}$ within each region by moving the dampers and observing the resulting value of $\mathrm{Ts}(\mathrm{x})$ and calculating $\mathrm{Qx}(\mathrm{x}) / \mathrm{Qs}$. Presumably, Tr and Ti would be fairly constant while this was being done, although this is not a requirement. Linear regression in each region of $\mathrm{x}$ should yield the same functional relationship between $\mathrm{Qx}(\mathrm{x}) / \mathrm{Qs}$ and $\mathrm{x}$ as the first method.

Since in this paper we do not have an actual system to work with, we will assume certain damper characteristics and model the performance of the mixing box. Linearization will then be performed in different regions of the $\mathrm{x}$ variable to simulate system identification. The governing equations are the two mass balance equations given above plus the equations:

$$
\begin{aligned}
& \mathrm{P} 1-\mathrm{P} 0=\operatorname{Re}(\mathrm{x}) \cdot \mathrm{Qe}^{2} \\
& \mathrm{P} 0-\mathrm{P} 2=\operatorname{Ri}(\mathrm{x}) \cdot \mathrm{Qi}^{2} \\
& \mathrm{P} 1-\mathrm{P} 2=\operatorname{Rx}(\mathrm{x}) \cdot \mathrm{Qx}^{2}
\end{aligned}
$$

Given values for P0, Qr/Qs, $\operatorname{Re}(\mathrm{x}), \operatorname{Ri}(\mathrm{x})$, and $\mathrm{Rx}(\mathrm{x})$, these equations can be solved for the variables $\mathrm{P} 1$, P2, Qe, Qx/Qs, and Qi/Qs .

Doing this, one finds for the variables of interest (Tan 2006):

$\operatorname{ratioQiToQs}(\mathrm{x})=1-\operatorname{ratioQxToQs}(\mathrm{x})$

ratioQeToQs(x) = Qr/Qs - ratioQxToQs(x) 
where:

$\operatorname{ratioQxToQs}(\mathrm{x})=\frac{-\mathrm{b}(\mathrm{x})-\left(\mathrm{b}(\mathrm{x})^{2}-4 \cdot \mathrm{a}(\mathrm{x}) \cdot \mathrm{c}(\mathrm{x})\right)^{0.5}}{2 \cdot \mathrm{a}(\mathrm{x})}$

$\mathrm{a}(\mathrm{x})=\operatorname{Ri}(\mathrm{x})+\operatorname{Re}(\mathrm{x})-\operatorname{Rx}(\mathrm{x})$

$\mathrm{b}(\mathrm{x})=-2 \cdot \operatorname{Ri}(\mathrm{x})-2 \cdot \operatorname{Re}(\mathrm{x}) \cdot \operatorname{ratioQ} \mathrm{rToQs}$

$c(x)=\operatorname{Ri}(x)+\operatorname{Re}(x) \cdot(\operatorname{ratioQrToQs})^{2}$

If we assume

$\operatorname{Ri}(x)=((1-A i) / A i) \cdot R i$,open + Ri,open $\cdot \exp (k d(1-x))$

$\operatorname{Re}(x)=((1-A e) / A e) \cdot R e, o p e n+R e, o p e n \cdot \exp (\operatorname{kd}(1-x))$

$R x(x)=((1-A x) / A x) \cdot R x, o p e n+R x, o p e n \cdot \exp (k d(1-x))$

where $\mathrm{Ai}, \mathrm{Ae}$, and $\mathrm{Ax}$ are the authorities of the inlet, exhaust, and recirculation dampers, then the first terms in the above three equations correspond to duct resistance and the second terms represent the resistance of the damper as a function of the control signal $\mathrm{x}$.

Assuming Ri,open = Re,open = Rx,open, it can be easily shown that Ri, Re, and $\mathrm{Rx}$ in the equations for $\mathrm{a}(\mathrm{x}), \mathrm{b}(\mathrm{x})$, and $\mathrm{c}(\mathrm{x})$ can be replaced by $\mathrm{Ri}^{\prime}, \mathrm{Re}^{\prime}$, and $\mathrm{Rx}^{\prime}$, where (Tan 2006):

$$
\begin{aligned}
& \operatorname{Ri}^{\prime}(x)=((1-A i) / A i)+\exp (k d(1-x)) \\
& \operatorname{Re}^{\prime}(x)=((1-A e) / A e)+\exp (\operatorname{kd}(1-x)) \\
& \operatorname{Rx}^{\prime}(x)=((1-A x) / A x)+\exp (\operatorname{kd}(1-x))
\end{aligned}
$$

Figure 3 shows the results of this mixing box model for values of $k d=7.578$ (Legg 1986), Ai $=0.1$, Ae $=0.5$, and $\mathrm{Ax}=0.2$ (Tan 2006), and assuming a balanced system, i.e., Qr $=$ Qs. 


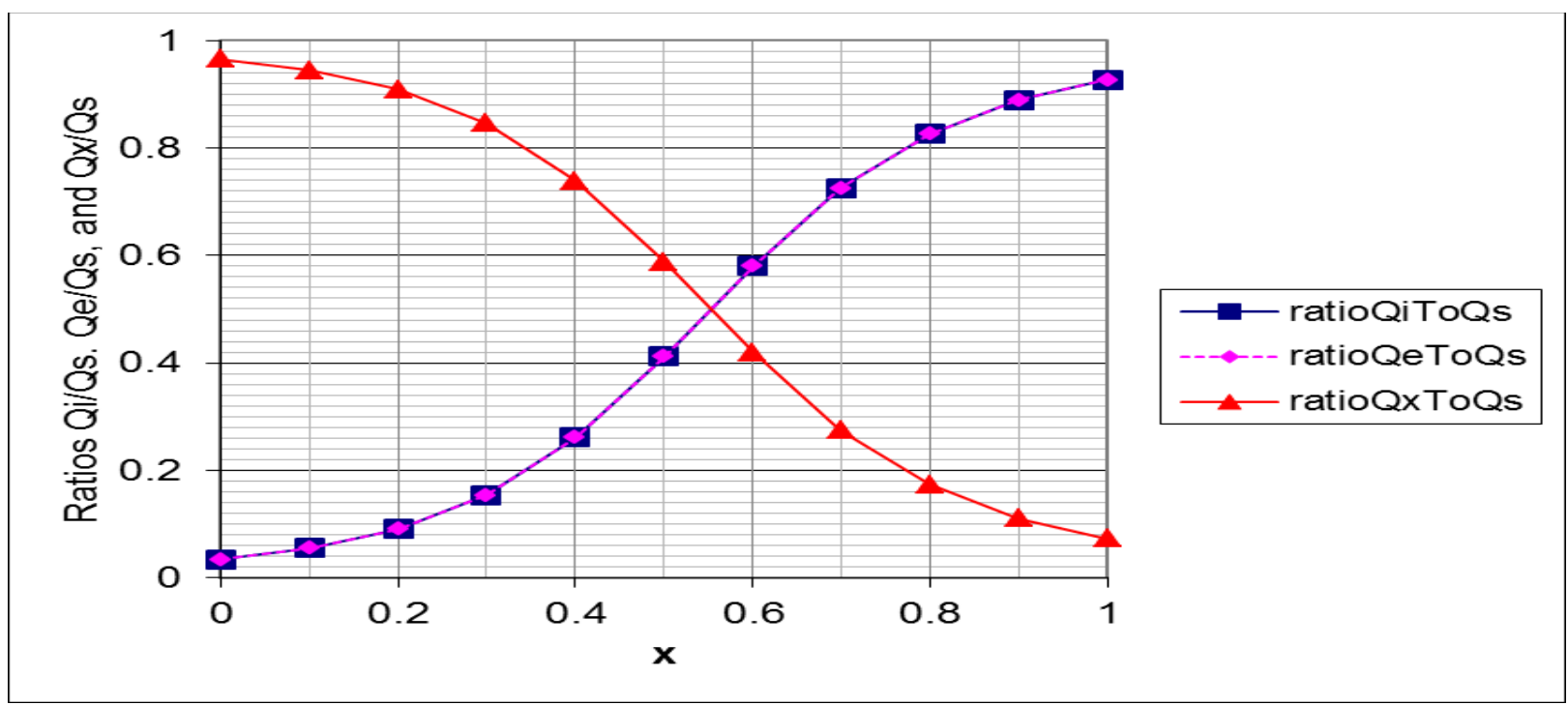

Figure 3. Ratios Qi/Qs, Qe/Qs, and Qx/Qs as a function of control signal x, for Qr/Qs = 1 .

For values of $\mathrm{Qr} / \mathrm{Qs}<1$, which corresponds to pressurizing the building, one finds that for small values of $\mathrm{x}$ it is possible to have the flow through the exhaust air damper reversed with some outside air coming in through this damper. This phenomenon was discussed in a paper by Seem et. al. (Seem, 2000) and a control strategy to prevent it was proposed. This undesirable effect, which can negatively affect indoor air quality, can also be avoided by setting an appropriate minimum opening on the inlet and exhaust dampers.

Although the work presented in this paper applies for any value of Qr/Qs and x where there is no reverse flow through the exhaust air damper, we will assume for the sake of simplifying the discussion that Qr = Qs. For this case, it is seen from Figure 3 that the performance of the dampers as a function of $\mathrm{x}$ can be divided into three almost linear regions. They are $0<=\mathrm{x}<=0.3,0.3<\mathrm{x}<=0.7$, and $0.7<\mathrm{x}<=1$. Using actual data from a real mixing box, one could then use linear regression in these three regions to obtain a piecewise model of the mixing box performance as a function of $\mathrm{x}$. However, since we are dealing in this paper with an idealized mixing box model, we will use straight line interpolation between end points to approximate the results of system identification using linear regression. Assuming maximum and minimum values of $\mathrm{Qx}(\mathrm{x}) / \mathrm{Qs}$ equal to 1.0 and 0.05 at $\mathrm{x}=1$ and $\mathrm{x}=0$, respectively, we define:

$$
\begin{aligned}
& \mathrm{a} 1=1 \\
& \mathrm{a} 2=\operatorname{ratioQxToQs}(0.3) \\
& \mathrm{a} 3=\operatorname{ratioQxToQs}(0.7) \\
& \mathrm{b} 1=\frac{\operatorname{ratioQxToQs}(0.3)-1}{(0.3-0)} \\
& \mathrm{b} 2=\frac{\operatorname{ratioQxToQs}(0.7)-\operatorname{ratioQxToQ}(0.3)}{(0.7-0.3)}
\end{aligned}
$$




$$
\mathrm{b} 3=\frac{0.05-\text { ratioQxToQs }(0.7)}{(1-0.7)}
$$

where

$$
\operatorname{ratioQxToQs~}(\mathrm{x})=\frac{-\mathrm{b}(\mathrm{x})-\left(\mathrm{b}(\mathrm{x})^{2}-4 \cdot \mathrm{a}(\mathrm{x}) \cdot \mathrm{c}(\mathrm{x})\right)^{0.5}}{2 \cdot \mathrm{a}(\mathrm{x})}
$$

and calculate estimated ratios (EST) as follows:

ESTratioQxToQs1 $(x)=a 1+b 1(x)$

ESTratioQxToQs2 $(\mathrm{x})=\mathrm{a} 2+\mathrm{b} 2 \cdot(\mathrm{x}-0.3)$

ESTratioQxToQs3 $(\mathrm{x})=\mathrm{a} 3+\mathrm{b} 3 \cdot(\mathrm{x}-0.7)$

ESTratioQxToQs $(\mathrm{x})=$ ESTratioQxToQs1(x) for $\mathrm{x}<0.3$

ESTratioQxToQs $(\mathrm{x})=$ ESTratioQxToQs2 $(\mathrm{x})$ for $0.3 \leq \mathrm{x}<0.7$

ESTratioQxToQs $(\mathrm{x})=$ ESTratioQxToQs3(x) for $\mathrm{x} \geq 0.7$

ESTratioQiToQs $(\mathrm{x})=$ 1- ESTratioQxToQs $(\mathrm{x})$

ESTratioQeToQs $(\mathrm{x})=\mathrm{Qr} / \mathrm{Qs}-$ ESTratioQxToQs $(\mathrm{x})$

The result of this linear approximation is shown in Figure 4 and corresponds to what might be obtained by an intelligent agent performing system identification.

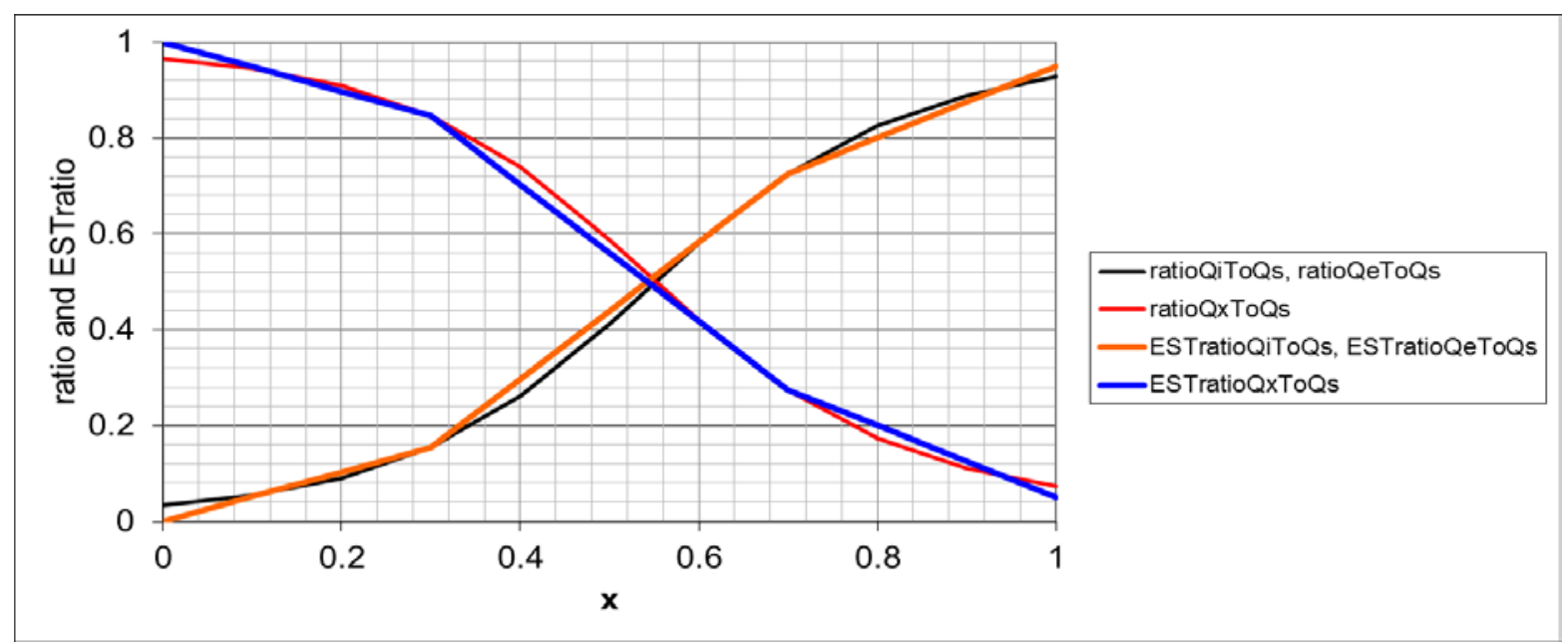

Figure 4. Comparison of linear approximations ESTratioQiToQs, ESTratioQeToQs, and ESTratioQxToQs with ratioQiToQs, ratioQeToQs, and ratioQxToQs as a function of control signal, x. 
System identification introduces some errors in the predicted performance, and these errors will affect the detection of real faults. Using the mixing box model defined above, the supply air temperature can be calculated using:

$$
\operatorname{Ts}(\mathrm{x}, \mathrm{Ti})=\frac{\operatorname{ratioQxToQs}(\mathrm{x}) \cdot \operatorname{Tr}+\operatorname{ratioQiToQs}(\mathrm{x}) \cdot \mathrm{Ti}}{\operatorname{ratioQxToQs}(\mathrm{x})+\operatorname{ratioQiToQs}(\mathrm{x})}
$$

Similarly, the supply air temperature predicted by the linear approximation of the real model is given by:

$$
\operatorname{ESTTs}(\mathrm{x}, \mathrm{Ti})=\frac{\operatorname{ESTratioQxToQs}(\mathrm{x}) \cdot \operatorname{Tr}+\operatorname{ESTratioQiToQs}(\mathrm{x}) \cdot \operatorname{Ti}}{\text { ESTratioQxToQs }(\mathrm{x})+\operatorname{ESTratioQiToQs}(\mathrm{x})}
$$

The difference between these two estimates corresponds to the error likely to be introduced by the system identification process. Figure 5 shows this error for values of Ti equal to $-8.9{ }^{\circ} \mathrm{C}, 0{ }^{\circ} \mathrm{C}$, and $8.9^{\circ} \mathrm{C}$, respectively. Also shown in these figures are errors of $+1.7^{\circ} \mathrm{C}$ and $-1.7^{\circ} \mathrm{C}$.
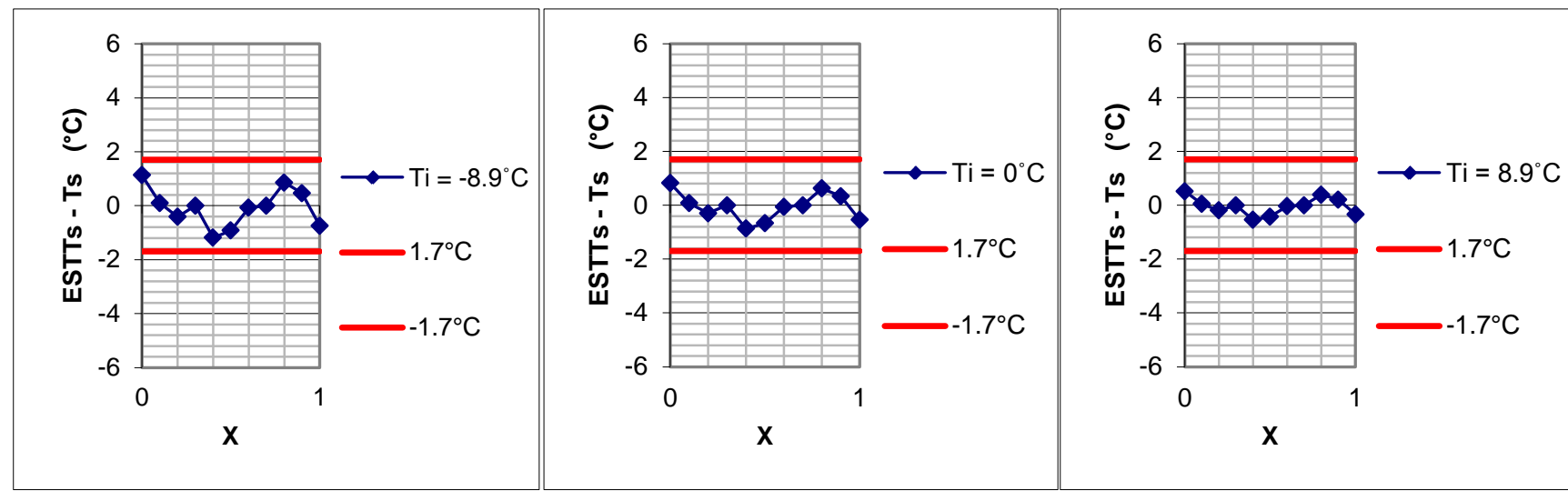

Figure 5. Difference between ESTTs and Ts corresponding to errors likely to be introduced by the system identification process. Figures, from left to right, are for values of $\mathrm{Ti}=-8.9{ }^{\circ} \mathrm{C}, 0{ }^{\circ} \mathrm{C}$, and $8.9{ }^{\circ} \mathrm{C}$.

Results for different values of Ti show that faults which result in differences between the actual supply air temperature and the predicted supply air temperature (based upon the identified model without faults) of less than $\pm 1.7^{\circ} \mathrm{C}$ cannot be detected because of the error resulting from system identification based upon linear approximations. On the other hand, faults resulting in differences equal to or greater than 
$\pm 1.7^{\circ} \mathrm{C}$ should be detectable. This is illustrated below for a stuck recirculation air damper. It is assumed that the damper is stuck $40 \%$ open, corresponding to $\mathrm{x}=0.6$.

Solving the mixing box model equations with this fault present, yields the performance results shown in Figure 6. The variables ratiofQxToQs, ratiofQeToQs, and ratiofQiToQs are the ratios of the recirculation, exhaust, and inlet air flow rates to the supply air flow rate with the fault present for different values of the control signal, $x$.

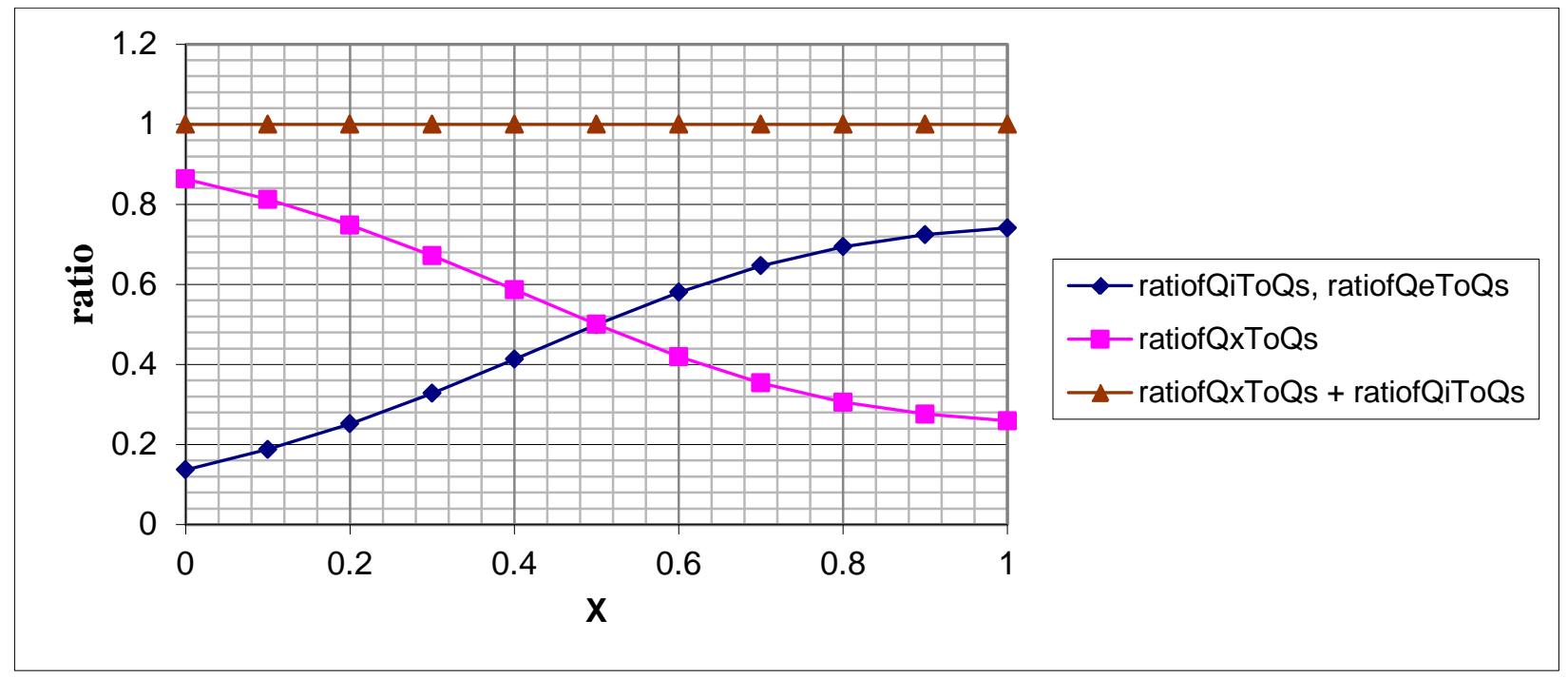

Figure 6. Results from mixing box model when the recirculation air damper is stuck $40 \%$ open, corresponding to $\mathrm{x}=0.6$.

\section{Using}

$\operatorname{Tsf}(x, \mathrm{Ti})=\frac{\operatorname{ratiofQxToQs}(\mathrm{x}) \cdot \mathrm{Tr}+\operatorname{ratiofQiToQs}(\mathrm{x}) \cdot \mathrm{Ti}}{\operatorname{ratiofQxToQs}(\mathrm{x})+\operatorname{ratiofQiToQs}(\mathrm{x})}$

one can find the value of $\mathrm{x}$ for which $\operatorname{Tsf}(\mathrm{x}, \mathrm{Ti})$ is equal to the supply air temperature setpoint, TaSP; we will call this value $\mathrm{y}$. If the calculated value of $\mathrm{y}$ is greater than 1 , it is set equal to 1 .

Similarly, the predicted value of the supply air temperature, at $\mathrm{x}=\mathrm{y}$, using the linearized model without faults, is given by:

TsPredicted $(y)=\frac{\text { ESTratioQxToQs }(y) \cdot \operatorname{Tr}+\text { ESTratioQiToQs }(y) \cdot T i}{\text { ESTratioQxToQs }(y)+\text { ESTratioQiToQs }(y)}$ 
and the observed error in the supply air temperature is:

TsObservedError $=$ Tsf $(\mathrm{y}, \mathrm{Ti})-$ TsPredicted $(\mathrm{y})$

This observed supply air temperature error is shown in Figure 7 for a supply air temperature setpoint, TaSP, equal to $12.8{ }^{\circ} \mathrm{C}$ and values of Ti equal to $-8.9{ }^{\circ} \mathrm{C},-4.4{ }^{\circ} \mathrm{C}, 0{ }^{\circ} \mathrm{C}, 4.4{ }^{\circ} \mathrm{C}$, and $8.9{ }^{\circ} \mathrm{C}$. Also shown in these figures are errors of $+1.7{ }^{\circ} \mathrm{C}$ and $-1.7^{\circ} \mathrm{C}$. One concludes from this graph that this fault (i.e., the recirculation air damper stuck $40 \%$ open) is likely to be masked by the error caused by system identification when $\mathrm{Ti}$ is between approximately $0.5^{\circ} \mathrm{C}$ and $7{ }^{\circ} \mathrm{C}$.

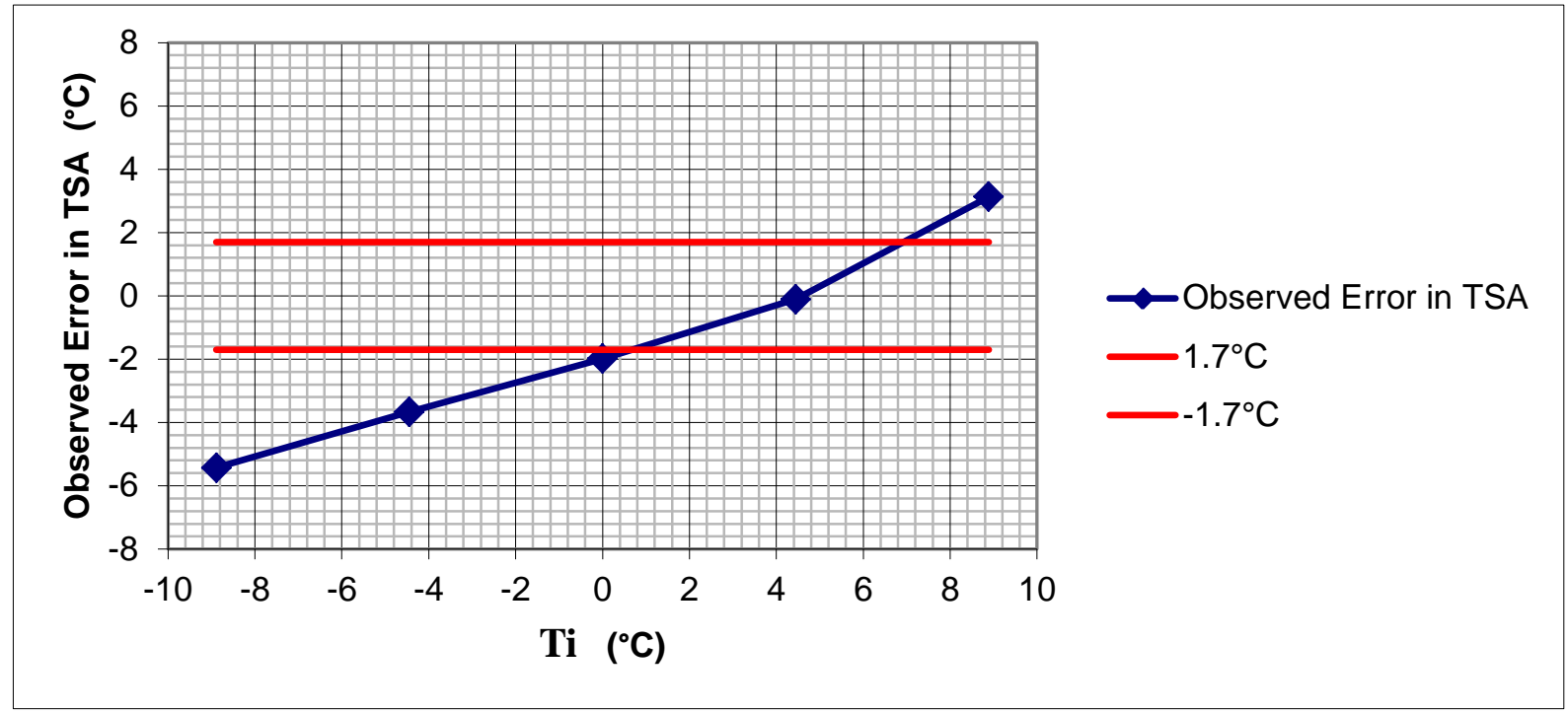

Figure 7. Observed error in supply air temperature for a recirculation air damper stuck at $40 \%$ open. The supply air temperature setpoint is $12.8{ }^{\circ} \mathrm{C}$ and values of Ti equal to $-8.9{ }^{\circ} \mathrm{C},-4.4{ }^{\circ} \mathrm{C}, 0{ }^{\circ} \mathrm{C}, 4.4{ }^{\circ} \mathrm{C}$, and $8.9{ }^{\circ} \mathrm{C}$.

The results obtained from the analysis of other recirculation damper faults and exhaust damper and inlet damper faults are presented in the section entitled Mixing Box Fault Detection Results.

\section{FAULT DETECTION BASED ON A SIMPLE COOLING COIL MODEL}

A simple cooling coil model developed by Wang (Wang 2004) will be used to examine which cooling coil faults can be detected and under what conditions. The output (cooling energy, $\mathrm{kW}$ ) of the cooling coil, Q = plf *Qmax, is given by: 
$\mathrm{Q}=\left[\frac{\mathrm{C} 1 \cdot \text { rateSA }}{\mathrm{e}} \underset{1+\mathrm{C} 2 \cdot\left(\frac{\text { rateSA }}{\text { rateChw }}\right)}{\mathrm{e}}\right] \cdot($ Tai - Tchw $)$

$\operatorname{rateSA}($ plf, Tai, Tao $)=\frac{\text { plf } \cdot \text { Qmax }}{(1.0 \cdot(\text { Tai }- \text { Tao }))}$

where

Qmax = maximum cooling coil capacity

plf $=$ part load factor $(\mathrm{Q} / \mathrm{Qmax})$

$\mathrm{C} 1=2.439$

$\mathrm{C} 2=0.498$

$\mathrm{e}=0.8$

Tai $=$ the entering air wet bulb temperature for a wet coil

Tao $=$ leaving air temperature $=$ Ts in Figure 2

Tchw = entering chilled water temperature

rateSA = supply air flow rate

rateChw $=$ chilled water flow rate

For the work considered in this paper, it is assumed that the cooling coil is dry (i.e., latent loads are not considered) and Tai in the above equations is equal to the entering dry bulb temperature.

Substituting the second equation for the rateSA into the first equation we find we have one equation with two unknowns, rateChw and Tao. We define the function A equal to:

$\mathrm{A}($ plf, Tai, Tao, Tchw, rateChw $)=\frac{\left(2.439 \cdot \text { rateSA }(\text { plf, Tai, Tao })^{0.8}\right) \cdot(\text { Tai }- \text { Tchw })}{1+0.498 \cdot\left(\frac{\text { rateSA }(\text { plf, Tai, Tao })}{\text { rateChw }}\right)^{0.8}}-$ plf.Qmax

Then if we know Tao, the chilled water mass flow rate can be calculated using:

MFRchwA(plf,Tai,Tao,Tchw) = root(A(plf, Tai, Tao, Tchw, rateChw), rateChw)

where $\operatorname{root}(\mathrm{A}(,,-,$, , rateChw $)$, rateChw $)$ gives the value of rateChw for which $\mathrm{A}=0$.

Similarly if rateChw is known, the temperature of the air leaving the coil (i.e., the supply air temperature, Ts) can be calculated using:

TempAirOutA(plf, Tai, Tchw, rateChw) = root(A(plf, Tai, Tao, Tchw, rateChw), Tao)

where $\operatorname{root}\left(\mathrm{A}\left(,, \ldots, \mathrm{Tao}_{-},{ }_{-}\right)\right.$, Tao) gives the value of Tao for which $\mathrm{A}=0$. 
In the above equations, a single " $\mathrm{A}$ " at the end of MFRchwA and TempAirOutA is used to indicate that the chilled water flow rate and leaving air temperature are calculated using the coil model given above that was developed by Wang (Wang 2004).

With closed loop control, the controller adjusts the chilled water flow rate, rateChw, through the cooling coil to maintain the supply air temperature at the supply air setpoint. As long as there are no faults present and the cooling coil valve is not fully open or fully closed, this should result in a chilled water flow given by MFRchwA(plf, Tai, Tao, Tchw) with Tao set equal to TaoSP. If this value of MFRchwA is inserted for the variable rateChw in the equation for TempAirOutA(plf, Tai, Tchw, rateChw), it will result in a value of TempAirOutA equal to the supply air temperature setpoint. This is shown in the Figure 8.

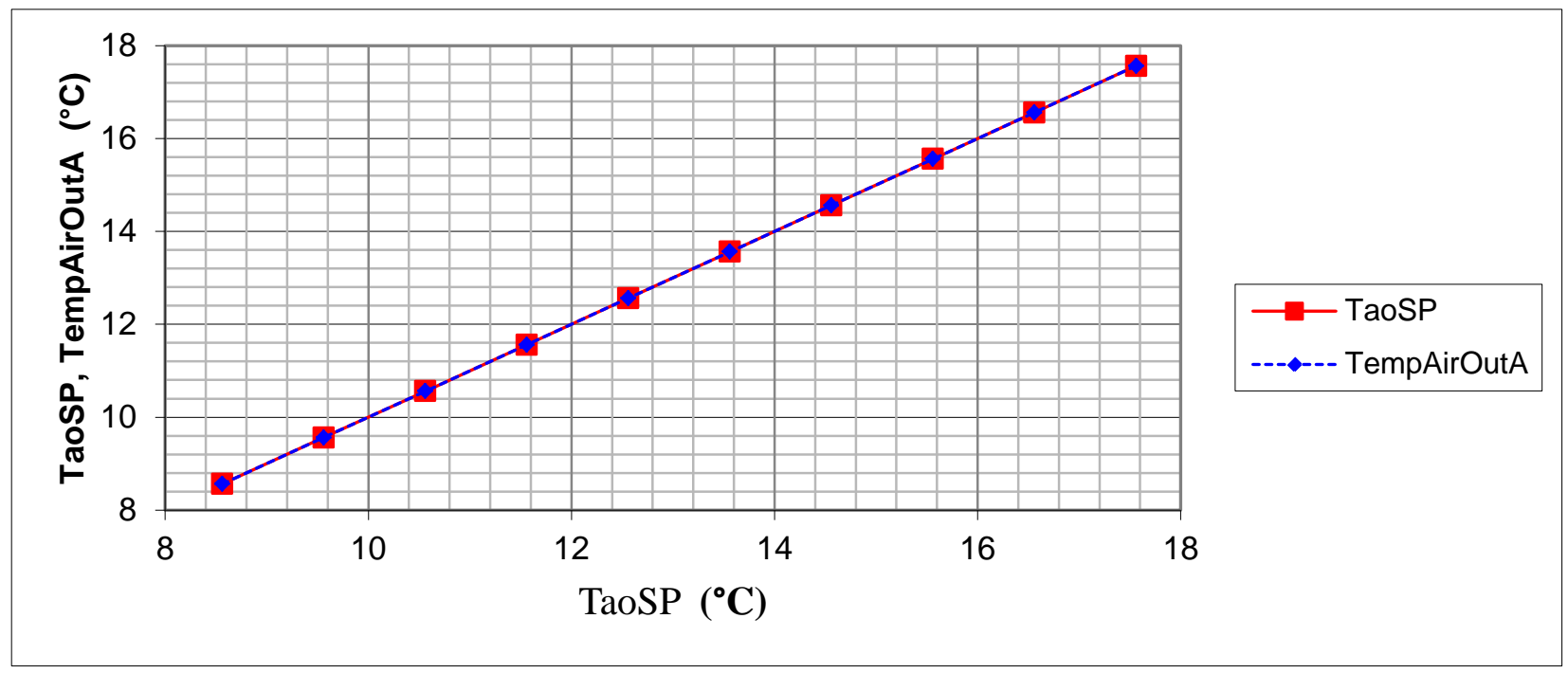

Figure 8. When no fault is present, the calculated value of TempAirOutA equals the supply air temperature setpoint, TaoSP.

If a fault was present (e.g., an offset error in the supply air temperature sensor), the value of rateChw calculated would be different from the value calculated without the fault. If this new (fault present) value of rateChw is inserted in the "fault free" equation for TempAirOutA, the resulting value of TempAirOutA would diverge from the supply air temperature setpoint. This divergence can be used to detect the presence of a fault.

A problem occurs when the supply air temperature setpoint, TaoSP, approaches the temperature of the chilled water entering the cooling coil, Tchw. For a fixed cooling coil capacity, this causes the chilled water mass flow rate through the cooling coil to rapidly rise and results in flow rates that are unrealistic. This is shown in Figure 9 for Tchw $=5.56{ }^{\circ} \mathrm{C}$. Also shown in this figure is the calculated design chilled water flow rate, mchwDesign, based upon a $4.44{ }^{\circ} \mathrm{C}$ rise in the temperature of the chilled water as it passes through the cooling coil. 


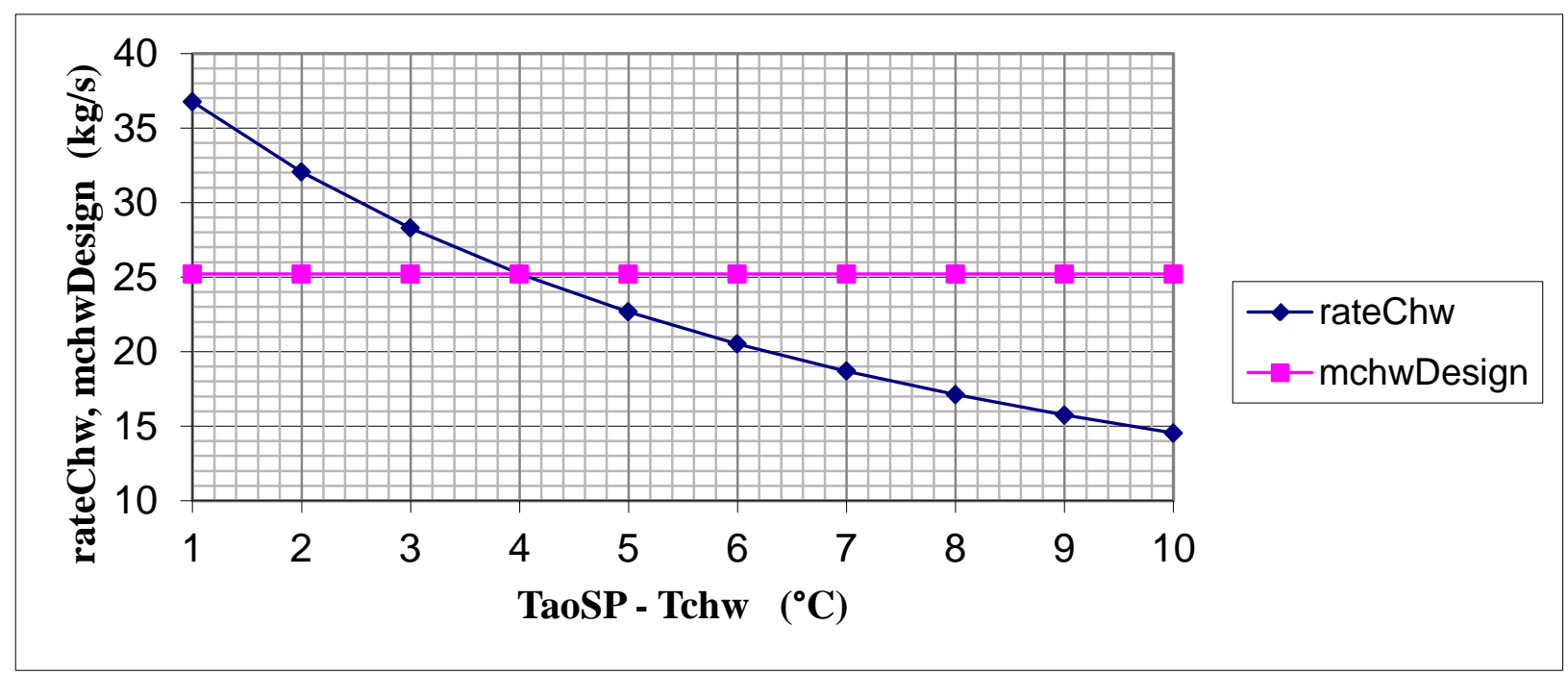

Figure 9. Chilled water flow rate, rateChw, and mchwDesign as a function of TaoSP - Tchw.

This problem will be avoided by requiring that TaoSP $-\mathrm{Tchw}>=3^{\circ} \mathrm{C}$, which allows for a maximum chilled water flow rate only slightly above the design flow rate. This restriction on how close TaoSP can approach Tchw will be employed in the remainder of this paper and becomes one of the conditions that must be met for the detection of cooling coil faults by the method described in this paper.

The equations given above for the simple cooling coil model present some difficulties if one wants to use system identification to come up with an approximate model of a real cooling coil. This problem can be overcome by transforming the equations into those for an effectiveness model. The water side effectiveness for a cooling coil is defined as:

effectiveness $=($ Two - Tchw $) /($ Tai - Tchw $)$

\section{Using}

Two - Tchw $=$ DelTwater(plf,rateChw)

where

DelTwater $($ plf , rateChw $)=\frac{\text { plf } \cdot \text { Qmax }}{\text { rateChw } \cdot 4.2}$

and inserting

rateChw $=$ MFRchwA(plf, Tai, Tao, Tchw), 
we have:

EFFw(plf, Tai, Tao, Tchw $)=\frac{\text { DelTwater }(\text { plf, MFRchwA }(\text { plf, Tai, Tao, Tchw }))}{(\text { Tai }- \text { Tchw })}$

This gives EFFw as a function of plf, Tai, Tao, and Tchw.

Using the fact that

$($ Two - Tchw $) /($ Tai - Tchw $)=$ plf*Qmax $/($ rateChw*4.2*(Tai - Tchw $))=$ EFFw $($ plf,Tai,Tao,Tchw $)$

We can define:

AA $($ plf, Tai, Tao, Tchw, rateChw $)=$ plf· $\frac{\text { Qmax }}{4.2 \cdot \operatorname{rateChw} \cdot(\text { Tai }- \text { Tchw })}-$ EFFw (plf, Tai, Tao, Tchw $)$

Then, MFRchwAA and TempAirOutAA can be calculated using the following equations

MFRchwAA(plf, Tai, Tao, Tchw) = root(AA(plf, Tai, Tao, Tchw, rateChw), rateChw)

and

TempAirOutAA(plf, Tai, Tchw, rateChw) = root(AA(plf, Tai, Tao, Tchw, rateChw), Tao)

where MFRchwAA is the chilled water mass flow rate for a supply air temperature equal to Tao and TempAirOutAA is the supply air temperature resulting from a chilled water mass flow rate equal to rateChw. Here the "AA" at the end of MFRchwAA and TempAirOutAA is used to indicate that the chilled water flow rate and leaving air temperature are calculated using the water side effectiveness model.

This form of the cooling coil model is just as accurate as the original form. This is demonstrated by its ability to predict a supply air temperature equal to the supply air temperature setpoint when no faults are present. This is illustrated in Figure 10 where TempAirOutAA is plotted for various values of TaoSP, with rateChw replaced by the function MFRchwA, which is the chilled water mass flow rate given by the original cooling coil model without a fault present. 


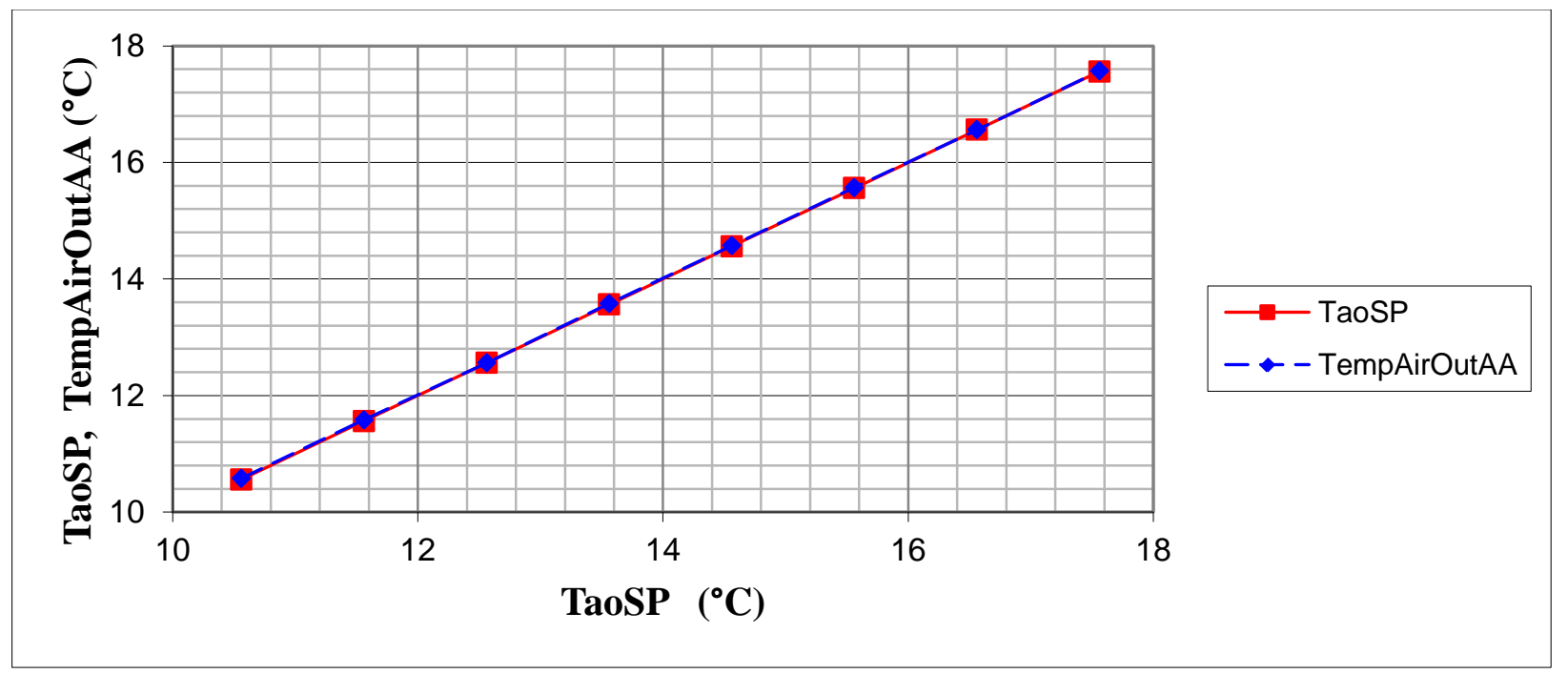

Figure 10. When no fault is present, the calculated value of TempAirOutAA equals the supply air temperature setpoint, TaoSP.

If one assumes Tai $=24{ }^{\circ} \mathrm{C}$ and plots this water side effectiveness, EFFw(plf, Tai, Tao, Tchw), as a function of $i=($ Tao - Tchw) for various values of plf and Tchw and as a function of plf for various values of $\mathrm{i}$ and Tchw, Figures 11 and 12 are obtained.

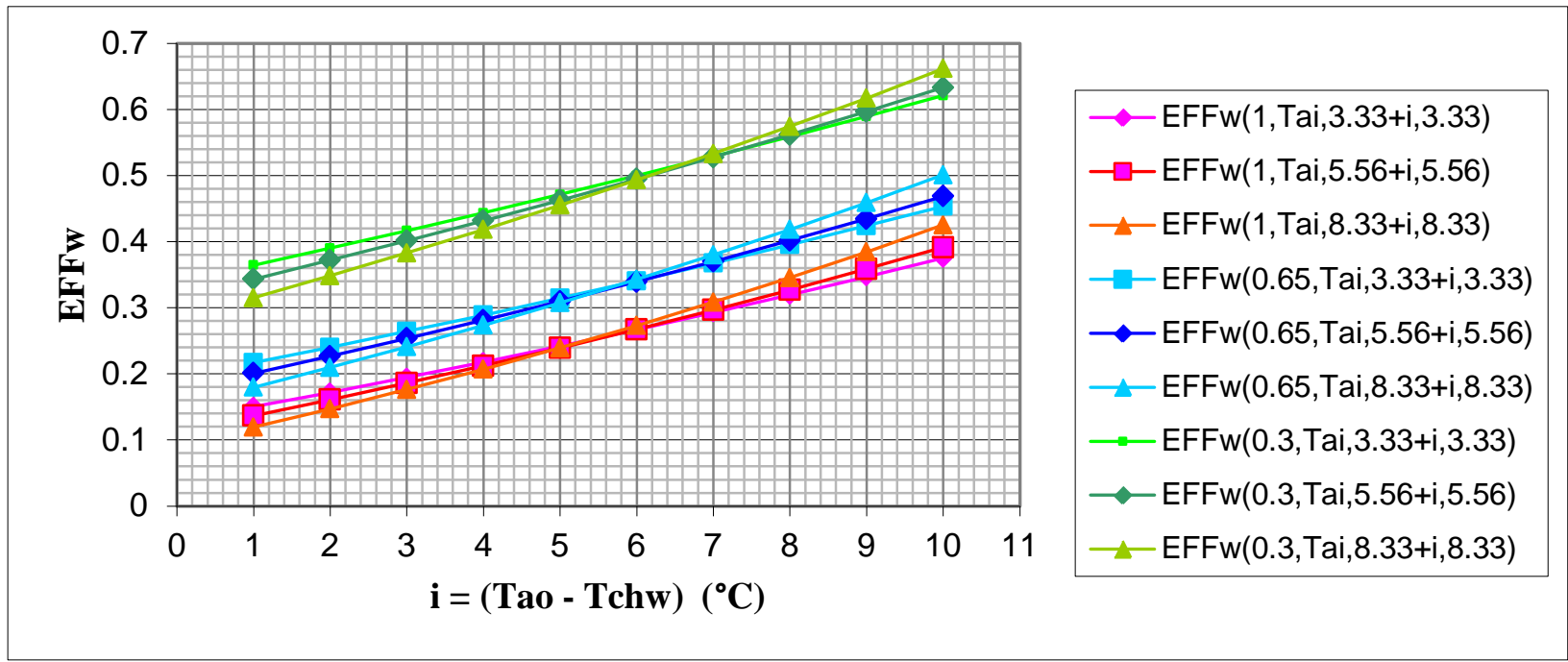

Figure 11. Plot of EFFw(plf, Tai, Tao, Tchw) as a function of $\mathrm{i}=($ Tao - Tchw $)$ for Tai $=24{ }^{\circ} \mathrm{C}$ and values of plf equal to $1,0.65$, and 0.3 and Tchw equal to $3.33{ }^{\circ} \mathrm{C}, 5.56{ }^{\circ} \mathrm{C}$, and $8.33{ }^{\circ} \mathrm{C}$. The bottom, middle, and top group of lines correspond to plf $=1,0.65$, and 0.3 , respectively. 


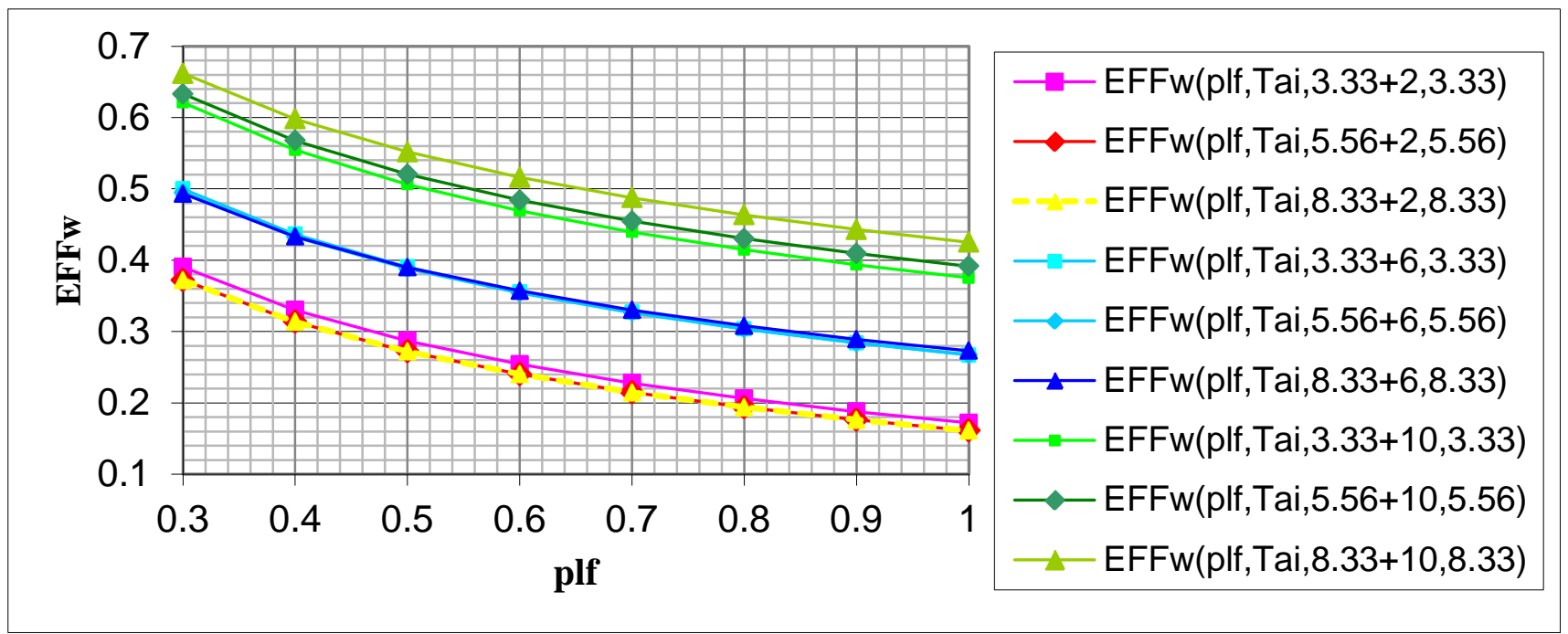

Figure 12. Plot of EFFw(plf, Tai, Tao, Tchw) as a function of plf for Tai $=24{ }^{\circ} \mathrm{C}$ and values of $\mathrm{i}=($ Tao - Tchw $)$ equal to $2{ }^{\circ} \mathrm{C}, 6{ }^{\circ} \mathrm{C}$, and $10{ }^{\circ} \mathrm{C}$ and Tchw equal to $3.33{ }^{\circ} \mathrm{C}, 5.56{ }^{\circ} \mathrm{C}$ and $8.33{ }^{\circ} \mathrm{C}$. The bottom, middle, and top group of lines correspond to i equal to $2{ }^{\circ} \mathrm{C}, 6{ }^{\circ} \mathrm{C}$, and $10{ }^{\circ} \mathrm{C}$, respectively.

These two figures show that EFFw is fairly linear over the range of $\mathrm{i}=($ Tao - Tchw) shown and can be divided into two approximately linear regions of plf. We will refer to the region $(0.3<=$ plf $<=0.6)$ as the " $\mathrm{A}$ " region, and the region $(0.6<$ plf $<=1$ ) as the " $\mathrm{B}$ " region. Values of plf below 0.3 will be ignored because of convergence problems in calculating EFFw when plf is small, and this becomes a second restriction on this fault detection method. Figures 11 and 12 also show that EFFw at Tchw $=5.56{ }^{\circ} \mathrm{C}$ provides a very good approximation for EFFw at other values of Tchw.

This demonstrates that if one had real data from a real coil, one should be able to use linear regression to arrive at an approximate water side effectiveness model. Since we are dealing in this paper with an ideal model, we will approximate the results of linear regression using linear interpolation.

The linear function EFFwAi3 (where "A" indicates region " $\mathrm{A}$ ") is first calculated for Tchw $=5.56{ }^{\circ} \mathrm{C}$ and $\mathrm{i}=3$ by interpolating between values of EFFw at plf $=0.3$ and plf $=0.5$. EFFwBi3 (where " $\mathrm{B}$ " indicates region " $\mathrm{B}$ ") is then calculated for Tchw $=5.56{ }^{\circ} \mathrm{C}$ and $\mathrm{i}=3$ by interpolating between values of $\mathrm{EFFw}$ at plf $=0.7$ and plf $=0.9$. This process is then repeated for Tchw $=5.56{ }^{\circ} \mathrm{C}$ and $\mathrm{i}=7$ to calculate EFFwAi7 and EFFwBi7. This gives the following four equations:

$$
\begin{aligned}
& \text { EFFwAi3( plf, Tai) }:=\operatorname{EFFw}(0.3, \text { Tai, } 5.56+3,5.56)+(\text { plf }-0.3) \cdot \frac{\operatorname{EFFw}(0.5, \text { Tai, 5.56 }+3,5.56)-\operatorname{EFFw}(0.3, \mathrm{Tai}, 5.56+3,5.56)}{(0.5-0.3)} \\
& \text { EFFwBi3(plf, Tai) }:=\operatorname{EFFw}(0.7, \text { Tai, } 5.56+3,5.56)+(\text { plf }-0.7) \cdot \frac{\operatorname{EFFw}(0.9, \text { Tai, } 5.56+3,5.56)-\operatorname{EFFw}(0.7, \mathrm{Tai}, 5.56+3,5.56)}{(0.9-0.7)}
\end{aligned}
$$


$\operatorname{EFFwAi7}\left(\right.$ plf, Tai) $:=\operatorname{EFFw}(0.3$, Tai, $5.56+7,5.56)+($ plf -0.3$) \cdot \frac{\operatorname{EFFw}(0.5, \text { Tai, } 5.56+7,5.56)-\operatorname{EFFw}(0.3, \text { Tai, } 5.56+7,5.56)}{(0.5-0.3)}$

$\operatorname{EFFwBi7}\left(\right.$ plf, Tai) $:=\operatorname{EFFw}(0.7$, Tai, $5.56+7,5.56)+($ plf -0.7$) \cdot \frac{\operatorname{EFFw}(0.9, \text { Tai, } 5.56+7,5.56)-\operatorname{EFFw}(0.7, \text { Tai, } 5.56+7,5.56)}{(0.9-0.7)}$

These equations can be combined to give:

EFFwA (plf, Tai, i) $=$ EFFwAi3(plf, Tai) $+(\mathrm{i}-3) \cdot$ EFFwAi7( plf Tai) - EFFwAi3(plf, Tai)

$$
(7-3)
$$

$\operatorname{EFFwB}\left(\right.$ plf, Tai, i) $=\operatorname{EFFwBi3(plf,Tai)}+(\mathrm{i}-3) \cdot \frac{\operatorname{EFFwBi7}(\text { plf Tai })-\operatorname{EFFwBi3(plf,Tai)}}{(7-3)}$

and

EFFwEST(plf,Tai,i) $=$ EFFwA(plf,Tai,i) for plf $<0.6$

EFFwEST(plf,Tai,i) $=$ EFFwB(plf,Tai,i) for plf $>=0.6$

Figure 13 shows there is good agreement between the full effectiveness model, EFFw, evaluated at Tai $=24{ }^{\circ} \mathrm{C}$ and Tchw equal to $3.33{ }^{\circ} \mathrm{C}, 5.56{ }^{\circ} \mathrm{C}$, and $8.33{ }^{\circ} \mathrm{C}$ and the linearized effectiveness model, EFFwEST evaluated at Tai $=24{ }^{\circ} \mathrm{C}$ and Tchw $=5.56{ }^{\circ} \mathrm{C}$. The bottom, middle and top group of lines correspond to $\mathrm{i}=(\mathrm{Tao}-\mathrm{Tchw})$ equal to $3{ }^{\circ} \mathrm{C}, 6{ }^{\circ} \mathrm{C}$, and $9{ }^{\circ} \mathrm{C}$, respectively.

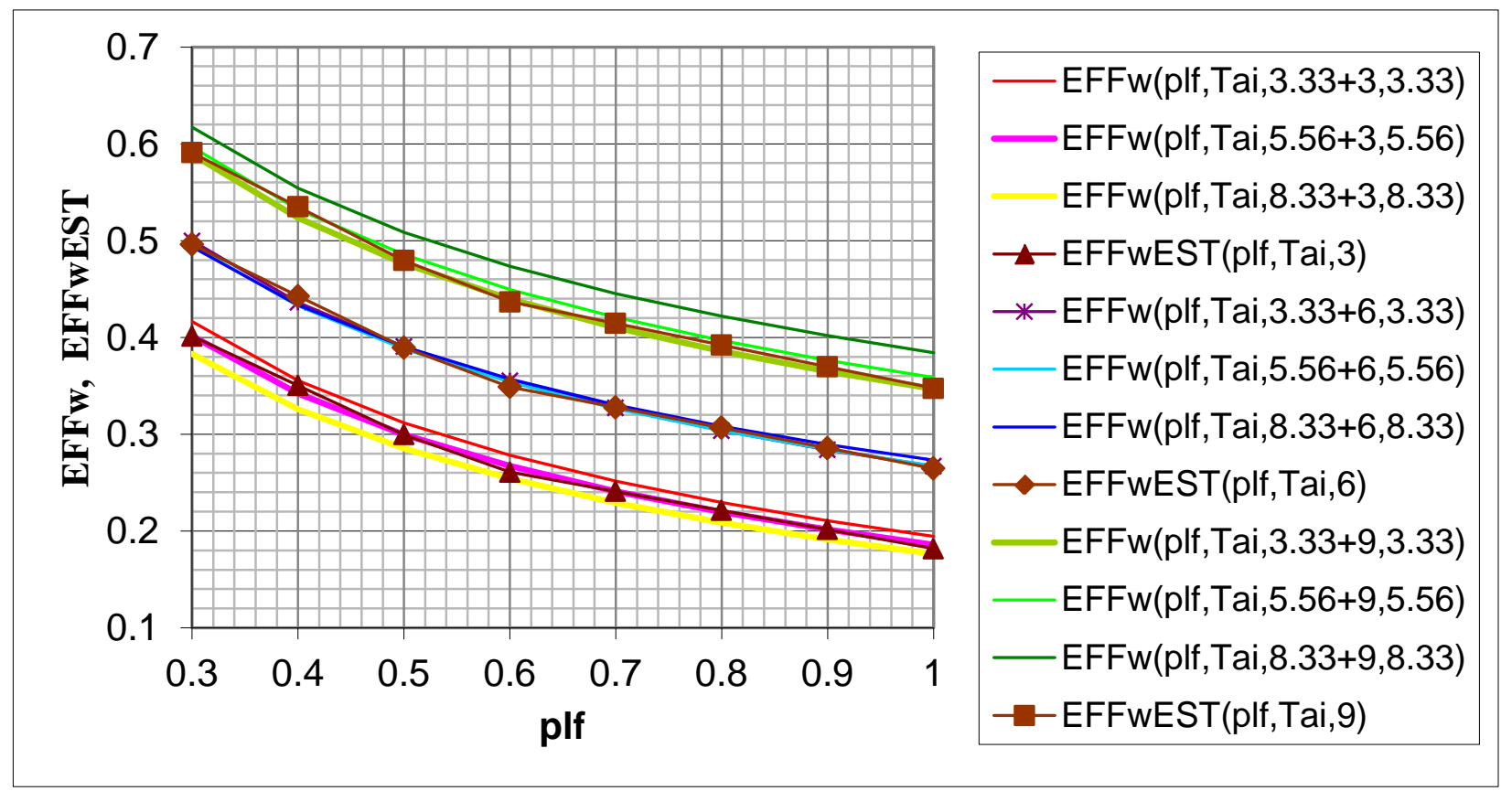

Figure 13. Comparison of the full effectiveness model with the approximate linear version as a function of plf 
Figure 14 shows EFFw as a function of $\mathrm{i}=($ Tao - Tchw $)$ for values of Tai equal to $24{ }^{\circ} \mathrm{C}$, Tao $+5{ }^{\circ} \mathrm{C}$, and Tao $+2{ }^{\circ} \mathrm{C}$ and EFFwEST as a function of $\mathrm{i}=\left(\right.$ Tao - Tchw) for values of Tai equal to $21{ }^{\circ} \mathrm{C}$. The left column of graphs shows the results when plf $=0.3$; the right column when plf $=1$. The top, middle, and bottom row of graphs correspond to Tchw equal to $3.4{ }^{\circ} \mathrm{C}, 5.56{ }^{\circ} \mathrm{C}$, and $10{ }^{\circ} \mathrm{C}$, respectively. The results show that when Tai is between Tao $+5{ }^{\circ} \mathrm{C}$ and $24{ }^{\circ} \mathrm{C}$, EFFw can be approximated with good results by EFFwEST with Tai equal to $21{ }^{\circ} \mathrm{C}$. However, when Tao and Tai get closer than $5{ }^{\circ} \mathrm{C}$, the agreement between EFFw and EFFwEST tends to break down. This is shown by the top line in all six graphs where Tai and Tao are only $2{ }^{\circ} \mathrm{C}$ apart. This places a third and fourth restriction on this fault detection approach, namely (Tai -Tao) $>5{ }^{\circ} \mathrm{C}$ and Tai $<=24{ }^{\circ} \mathrm{C}$, respectively.

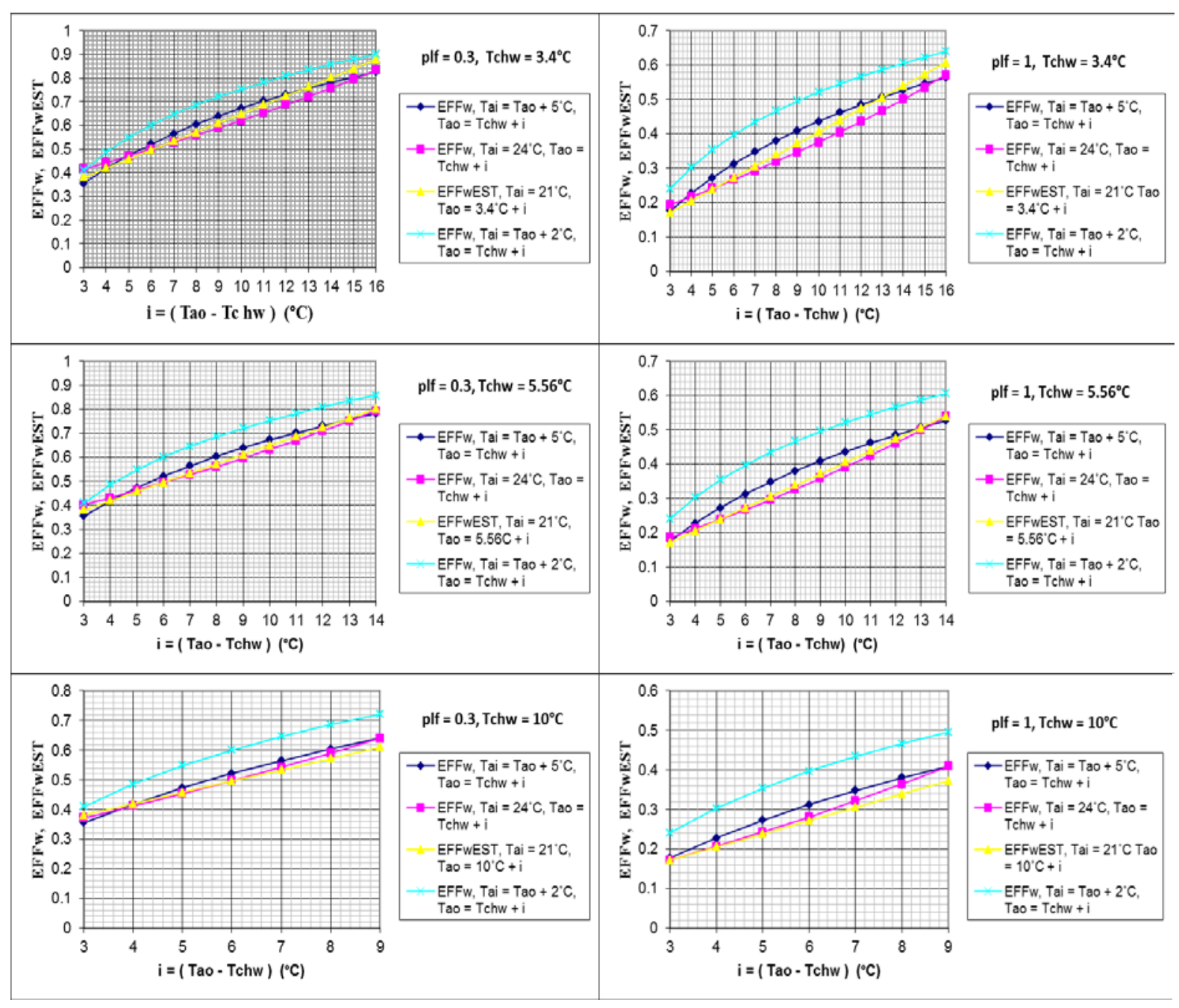

Figure 14. EFFwEST vs. i with Tai $=21^{\circ} \mathrm{C}$ and EFFw vs. $\mathrm{i}$ when Tai equal to Tao + $2{ }^{\circ} \mathrm{C}$, Tao $+5{ }^{\circ} \mathrm{C}$ and $24{ }^{\circ} \mathrm{C}$.

Thus EFFwEST, with Tai $=21^{\circ} \mathrm{C}$, can be used to predict Tao providing the four restrictions discussed previously are met. When no faults are present, the difference between the predicted value of Tao and 
the supply air temperature setpoint, TaoSP, is due to errors resulting from using an approximate linear effectiveness model and a value of Tai $=21{ }^{\circ} \mathrm{C}$.

Assuming (TaoSP - Tchw) $>=3$, plf $>=0.3{ }^{\circ} \mathrm{C}$, (Tai -TaoSP) $>5$, and Tai $<=24{ }^{\circ} \mathrm{C}$, one can calculate TempAirOutAAA using EFFwEST evaluated at Tai $=21{ }^{\circ} \mathrm{C}$.

AAA (plf, Tai, Tao, Tchw, rateChw) $=$ plf· $\frac{\text { Qmax }}{4.2 \cdot \operatorname{rateChw}(\text { Tai }- \text { Tchw })}-$ EFFwEST(plf, $21^{\circ} \mathrm{C}$, Tao - Tchw $)$

Then for a known value of rateChw, we have:

TempAirOutAAA(plf, Tai, Tao, Tchw, rateChw) = root(AAA(plf, Tai, Tao, Tchw, rateChw), Tao)

The "AAA" at the end of TempAirOutAAA is used to indicate that the leaving air temperature is calculated using the linearized water side effectiveness model, EFFwEST, with Tai set equal to $21{ }^{\circ} \mathrm{C}$.

Setting rateChw equal to the chilled water mass flow rate obtained using the original cooling coil model, MFRchwA without a fault present, we can calculate TempAirOutAAA and examine the effect of the errors introduced by using EFFwEST with Tai equal to $21^{\circ} \mathrm{C}$. Figures 15, 16, and 17 show for plf $=1$ the predicted value of the supply air temperature, TempAirOurAAA, as a function of TaoSP when Tai = TaoSP $+5{ }^{\circ} \mathrm{C}$, Tai $=24{ }^{\circ} \mathrm{C}$, and a midpoint value, TaiMid, halfway between TaoSP $+5{ }^{\circ} \mathrm{C}$ and $24{ }^{\circ} \mathrm{C}$ for Tchw equal to $3.33{ }^{\circ} \mathrm{C}, 5.56{ }^{\circ} \mathrm{C}$, and $10{ }^{\circ} \mathrm{C}$, respectively. In each Figure, TaoSP ranges from Tchw + $3{ }^{\circ} \mathrm{C}$ to approximately $19{ }^{\circ} \mathrm{C}$, which is $5{ }^{\circ} \mathrm{C}$ below the maximum allowed value of Tai $=24{ }^{\circ} \mathrm{C}$. Lines showing TaoSP $\pm 1.3{ }^{\circ} \mathrm{C}$ are also shown in these Figures.

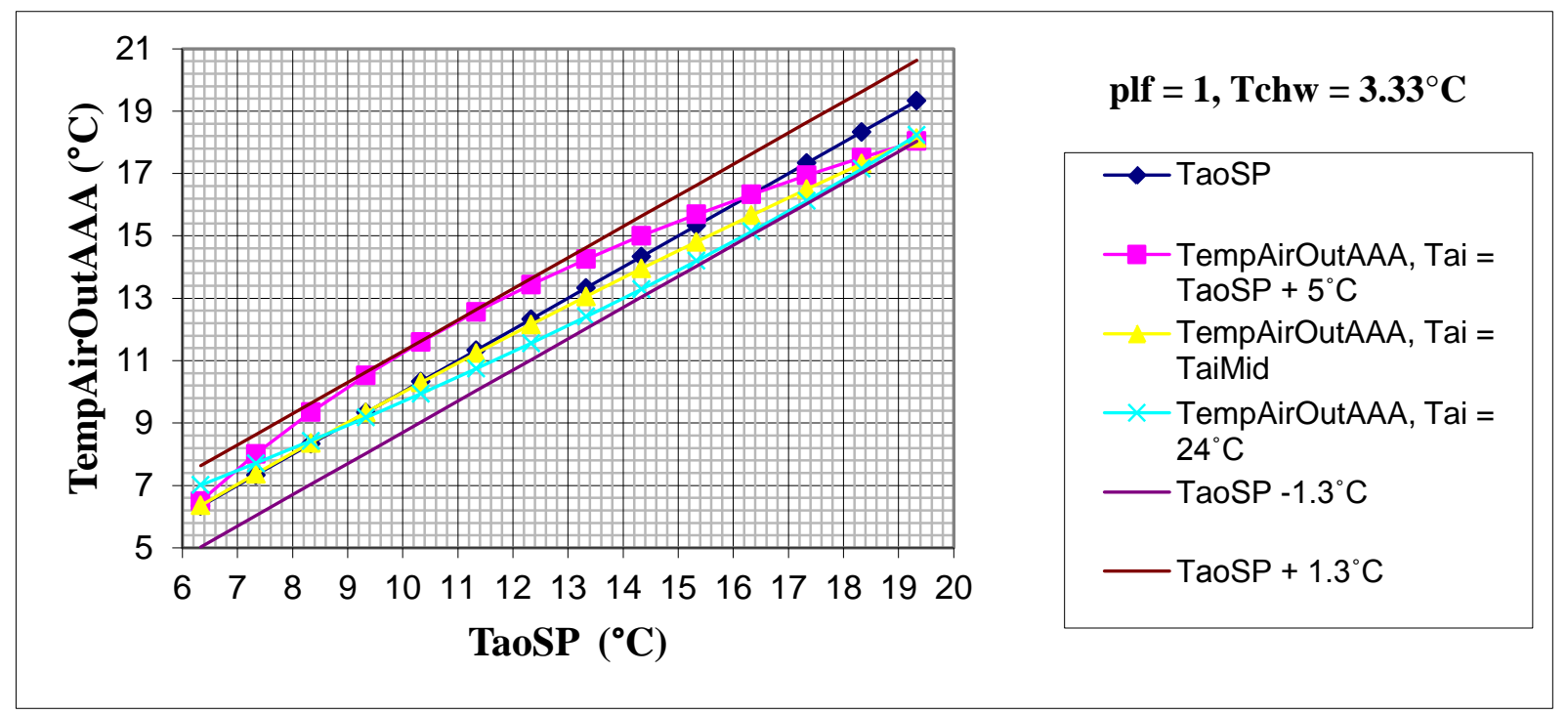

Figure 15. TempAirOurAAA vs. TaoSP for Tchw equal to $3.33{ }^{\circ} \mathrm{C}$, Tai $=$ TaoSP $+5{ }^{\circ} \mathrm{C}$, Tai $=24{ }^{\circ} \mathrm{C}$, and a mid-point value, TaiMid; lines TaoSP $\pm 1.3{ }^{\circ} \mathrm{C}$. 


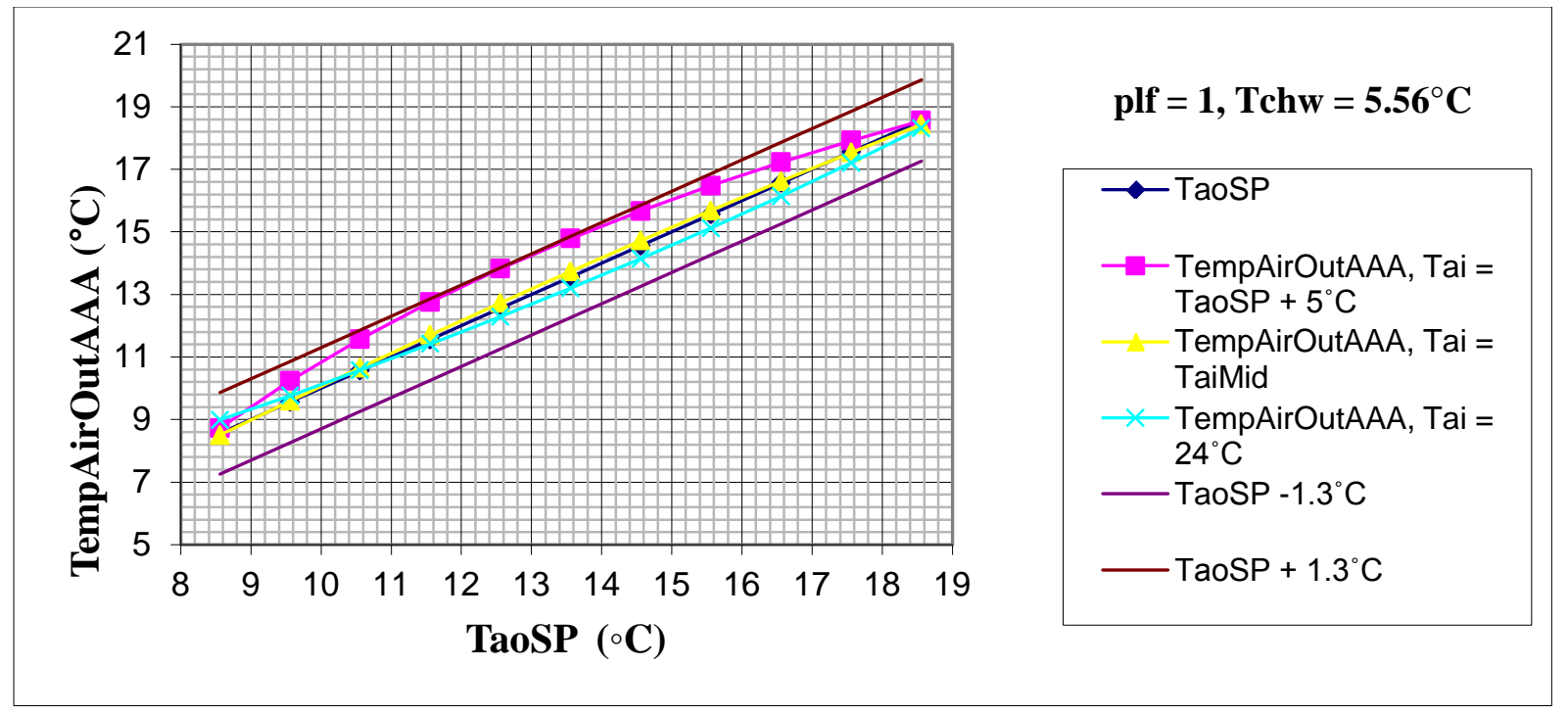

Figure 16. TempAirOurAAA vs. TaoSP for Tchw equal to $5.56{ }^{\circ} \mathrm{C}$, when Tai $=$ TaoSP + $5{ }^{\circ} \mathrm{C}$, Tai $=24{ }^{\circ} \mathrm{C}$, and a midpoint value, TaiMid; lines TaoSP $\pm 1.3{ }^{\circ} \mathrm{C}$.

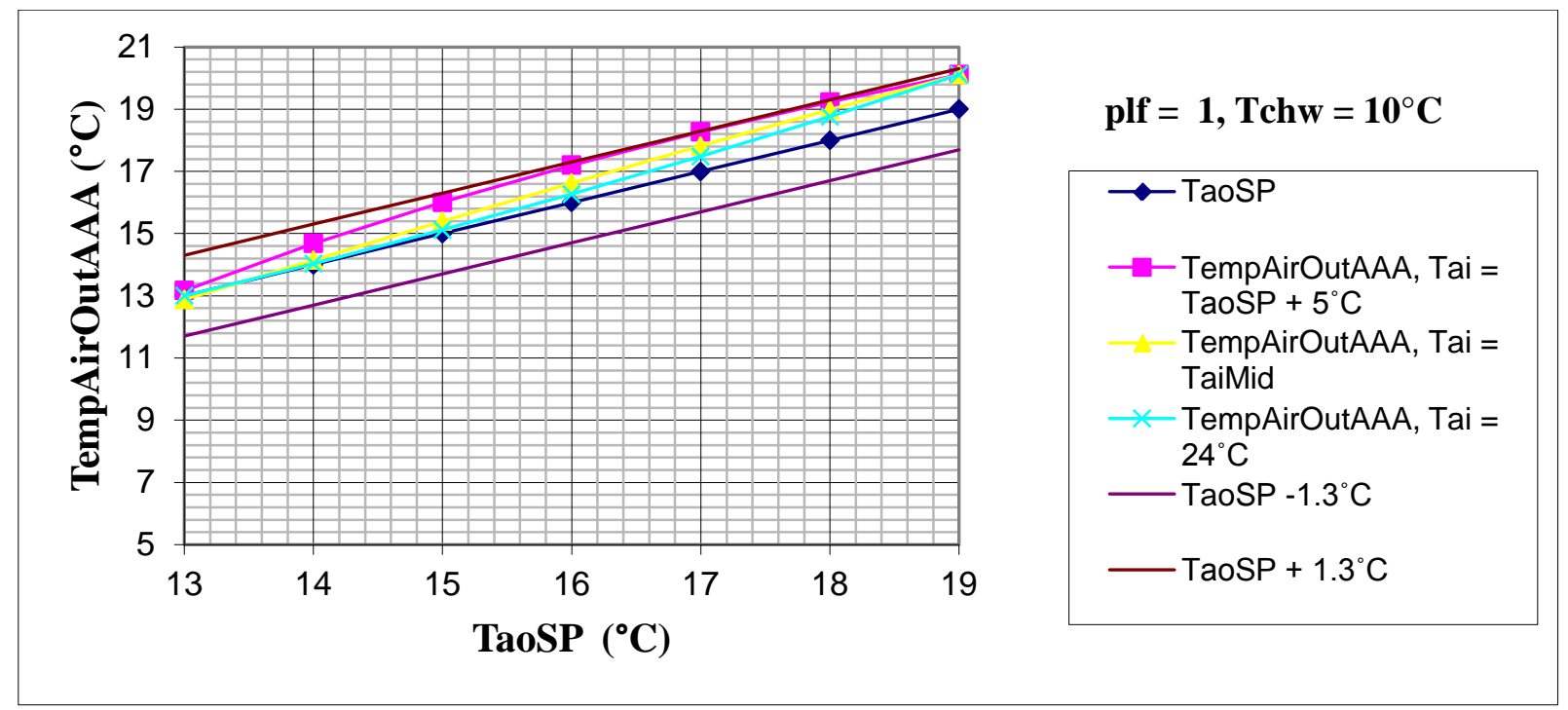

Figure 17. TempAirOurAAA vs. TaoSP for Tchw equal to $10{ }^{\circ} \mathrm{C}$, when Tai $=$ TaoSP $+5{ }^{\circ} \mathrm{C}$, Tai $=24{ }^{\circ} \mathrm{C}$, and a midpoint value, TaiMid; lines TaoSP $\pm 1.3^{\circ} \mathrm{C}$.

As illustrated by the curve corresponding to Tai = TaiMid, values of TempAirOutAAA for Tai > TaoSP $+5{ }^{\circ} \mathrm{C}$ and $<24{ }^{\circ} \mathrm{C}$ will generally lie between the values of TempAirOutAAA with Tai = TaoSP $+5{ }^{\circ} \mathrm{C}$ and TempAirOutAAA with Tai $=24{ }^{\circ} \mathrm{C}$. The exception is in regions where the lines for these two limiting cases cross, in which case the predicted value of TempAirOutAAA can be said to be 
"close by". This, however, does not appear to cause a significant problem. Values of plf $<1$ only bring the curves in the above figures closer together.

Based upon these results, we will assume for the remainder of this paper that when TaoSP $+5{ }^{\circ} \mathrm{C}<$ Tai $\leq 24{ }^{\circ} \mathrm{C}$ and the difference between the predicted value of supply air temperature, TempAirOutAAA, and the supply air temperature setpoint is equal to or more than $\pm 1.3{ }^{\circ} \mathrm{C}$, it is due to the presence of one or more faults. The detection of different cooling coil faults is discussed below in the section entitled Cooling Coil Fault Detection Results.

\section{MIXING BOX FAULT DETECTION RESULTS}

If the Recirculating Air damper is stuck in an open position, the mixing box controller will try to adjust the inlet and exhaust dampers to compensate and maintain the supply air temperature setpoint. The charts in Figure 18 show the observer error, TsObservedError, in the supply air temperature for an open recirculation air damper (Dxf) stuck open at 20\%, 40\%, 60\%, and 80\%. The abrupt changes in slope seen in some of the curves are due to the fact that $\mathrm{x}$ cannot be greater than 1 , which corresponds to the inlet and exhaust dampers being fully open.

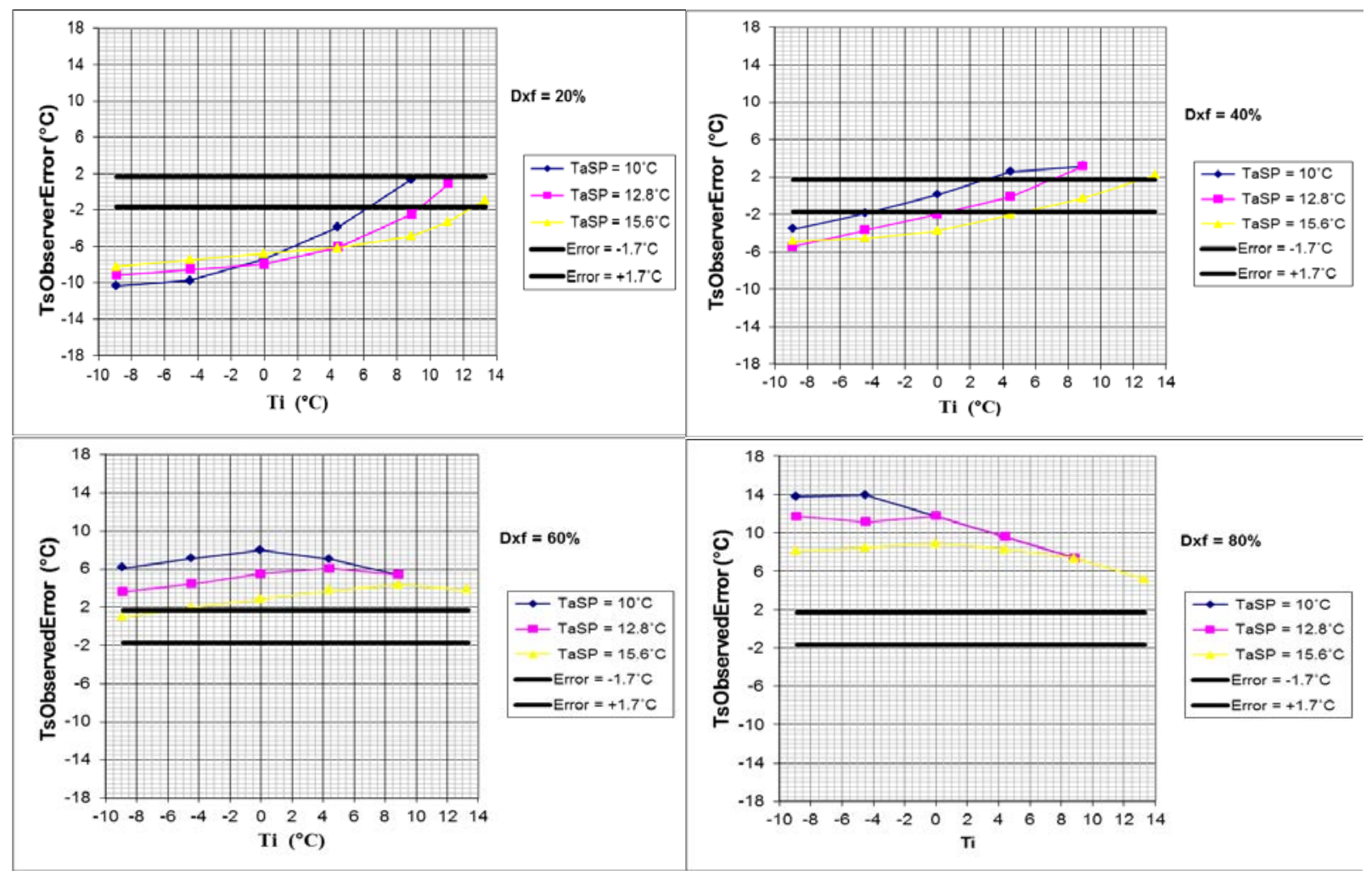

Figure 18. TsObservedError vs. inlet temperature for recirculation air damper being stuck open at $20 \%, 40 \%, 60 \%$, and $80 \%$. 
From this figure we see that under the following conditions it would be difficult to detect a stuck recirculation air damper fault (i.e., where TsObservedError is between $\pm 1.7^{\circ} \mathrm{C}$ of the supply air temperature setpoint) when:

- the recirculating air damper fault is stuck at $20 \%$ open and the supply air temperature setpoint is $10{ }^{\circ} \mathrm{C}, 12.8{ }^{\circ} \mathrm{C}$, or $15.6{ }^{\circ} \mathrm{C}$ and $\mathrm{Ti}$ is above (approximately) $6{ }^{\circ} \mathrm{C}, 9.5^{\circ}$, and $12.5^{\circ} \mathrm{C}$ respectively.

- the recirculating air damper fault is stuck at $40 \%$ open and the supply air temperature setpoint is $10{ }^{\circ} \mathrm{C}, 12.8{ }^{\circ} \mathrm{C}$, or $15.6{ }^{\circ} \mathrm{C}$ and $\mathrm{Ti}$ is between (approximately) $-4{ }^{\circ} \mathrm{C}$ and $3{ }^{\circ} \mathrm{C}, 0.5{ }^{\circ} \mathrm{C}$ and $7{ }^{\circ} \mathrm{C}$, and $5.5^{\circ} \mathrm{C}$ and $12{ }^{\circ} \mathrm{C}$, respectively.

- the recirculating air damper fault is stuck at $60 \%$ open and the supply air temperature setpoint is $15.6{ }^{\circ} \mathrm{C}$ and $\mathrm{Ti}$ is below (approximately) $-5{ }^{\circ} \mathrm{C}$,

However, while it may be difficult to detect a stuck recirculation air damper fault under the above conditions, it is still likely that this type of fault will sooner or later be detected since Ti will vary over a wide range with changes in the outside temperature.

Similar fault detection problems are found for stuck inlet and exhaust damper faults. In this case the mixing box controller will try to adjust the recirculating air damper to maintain the supply air temperature setpoint.

For TaSP $=10{ }^{\circ} \mathrm{C}$, TsObservedError is shown in Figure 19 for an inlet damper (Dif) stuck 20\% open and an outlet damper (Def) stuck 20\% open.

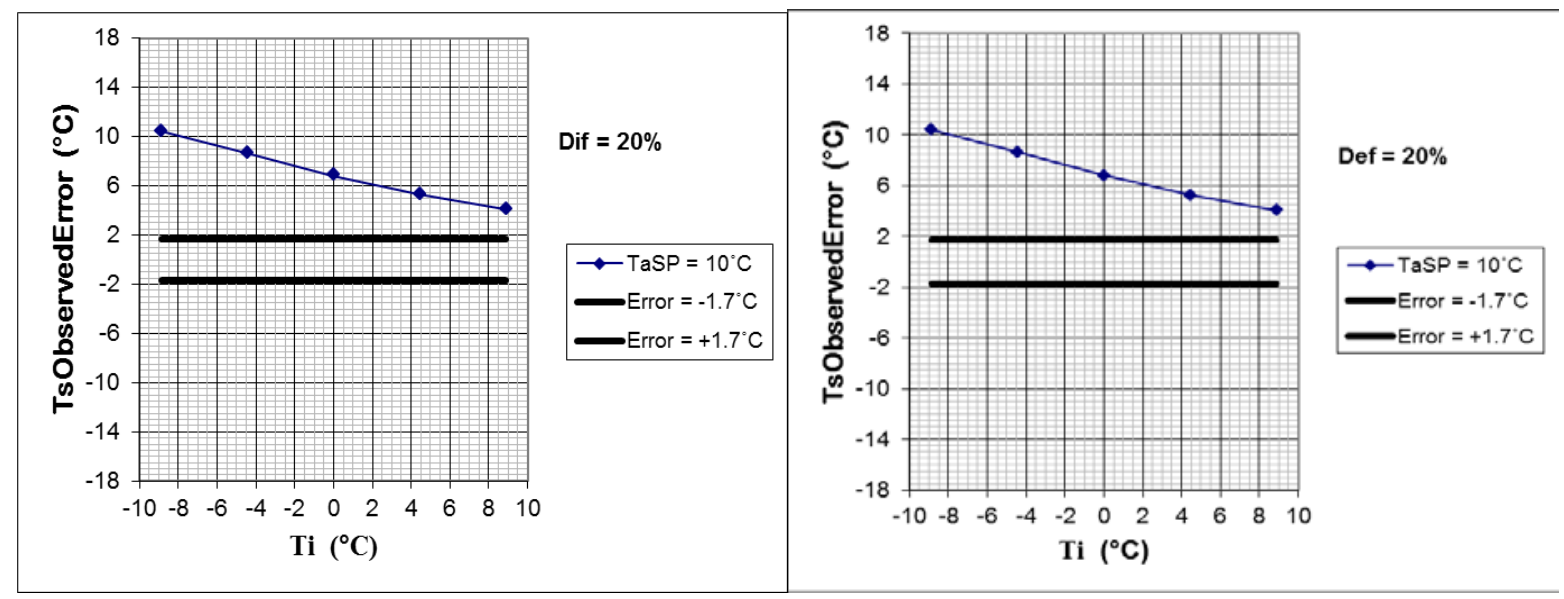

Figure 19. TsObservedError vs. inlet temperature with TaSP $=10{ }^{\circ} \mathrm{C}$. Left graph is for an inlet air damper stuck open 20\%; right graph is for an exhaust air damper stuck open $20 \%$.

We see that stuck inlet and stuck exhaust air dampers have the same effect on TsObservedError and are thus indistinguishable from each other without additional information. One can also conclude from this figure that for TaSP $=10{ }^{\circ} \mathrm{C}$, a fault involving either a $20 \%$ stuck open inlet or a $20 \%$ stuck open outlet damper should be readily detected. TsObservedError is shown in Figure 20 for $\mathrm{TaSP}=10{ }^{\circ} \mathrm{C}$ and the 
inlet air damper (Dif) stuck open 40\%, 50\%, 60\%, and 80\%. Identical results would be obtained for an exhaust damper stuck open.

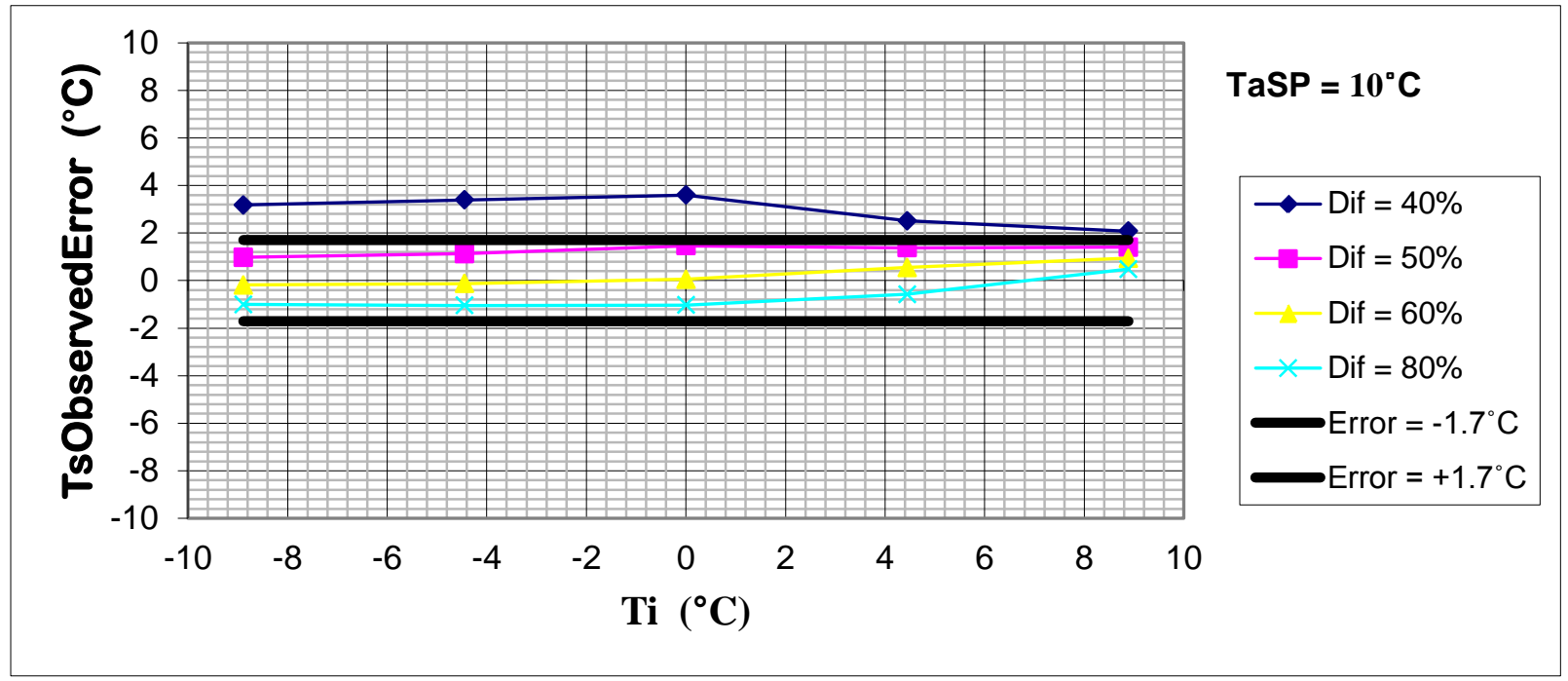

Figure 20. TsObservedError is shown for TaSP $=10{ }^{\circ} \mathrm{C}$ and the inlet air damper stuck open $40 \%, 50 \%, 60 \%$, and $80 \%$.

One finds that for TaSP $=10{ }^{\circ} \mathrm{C}$ a fault involving an inlet air damper (or an exhaust air damper) stuck open $40 \%$ is likely to be detected; however, there are serious problems in detecting inlet dampers (or exhaust dampers) that are stuck at $50 \%$ or more open. Changing TaSP from $10{ }^{\circ} \mathrm{C}$ to $15.6{ }^{\circ} \mathrm{C}$ has only a slight effect on TsObservedError. This is shown in Figure 21 for an inlet air damper that is stuck open $60 \%$.

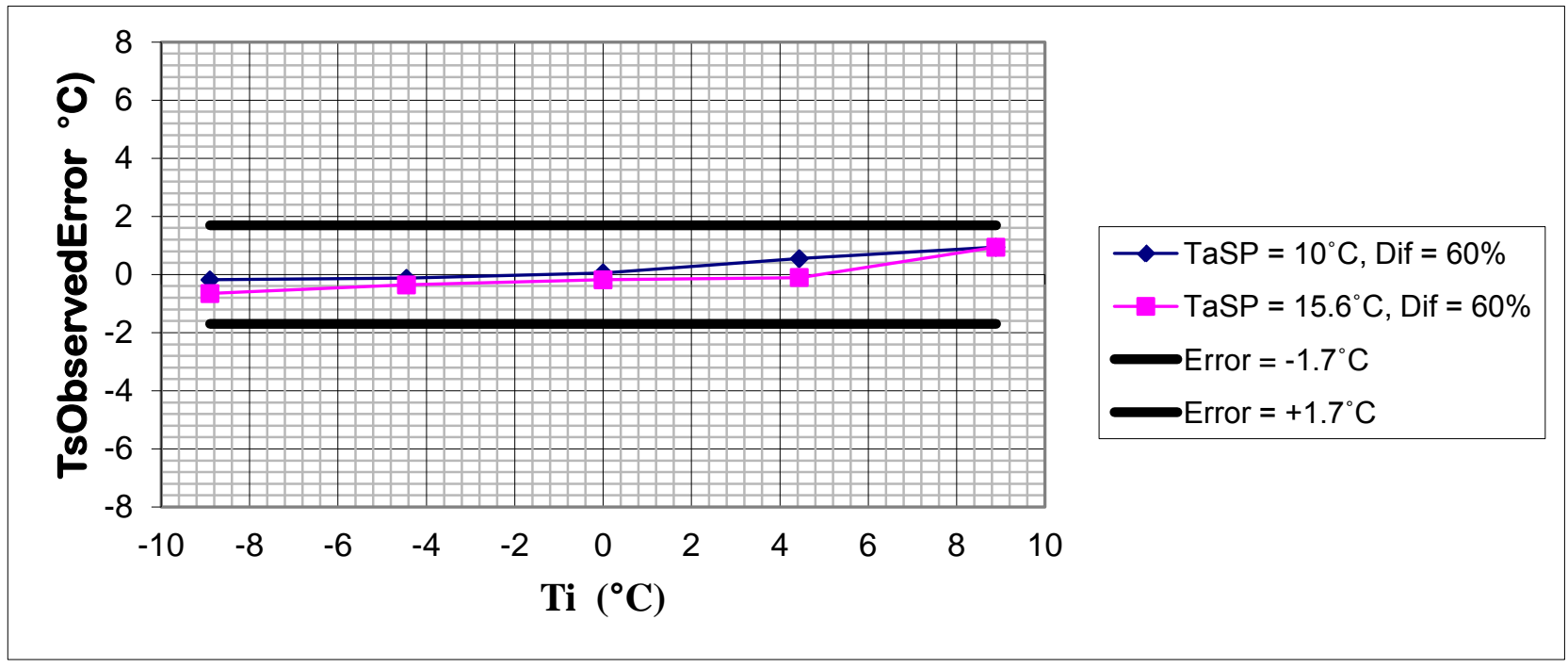

Figure 21. TsObservedError with an inlet air damper stuck open $60 \%$ and TaSP equal to $10{ }^{\circ} \mathrm{C}$ and $15.6{ }^{\circ} \mathrm{C}$. 
When the inlet and exhaust dampers are both stuck open, the mixing box controller will try to adjust the recirculating air damper to maintain the supply air temperature setpoint. Figure 22 shows the results of having both the inlet (Dif) and exhaust (Def) dampers stuck open at 20\%, 40\%, 60\%, and 80\%. We see from this Figure that when both dampers are stuck open $60 \%$, it will be difficult to detect the fault when $\mathrm{Ti}$ is greater than $-4.5^{\circ} \mathrm{C}$. Similarly, when both dampers are stuck open at $80 \%$, it will be difficult to detect the fault when $\mathrm{Ti}$ is greater than $4.5^{\circ} \mathrm{C}$.

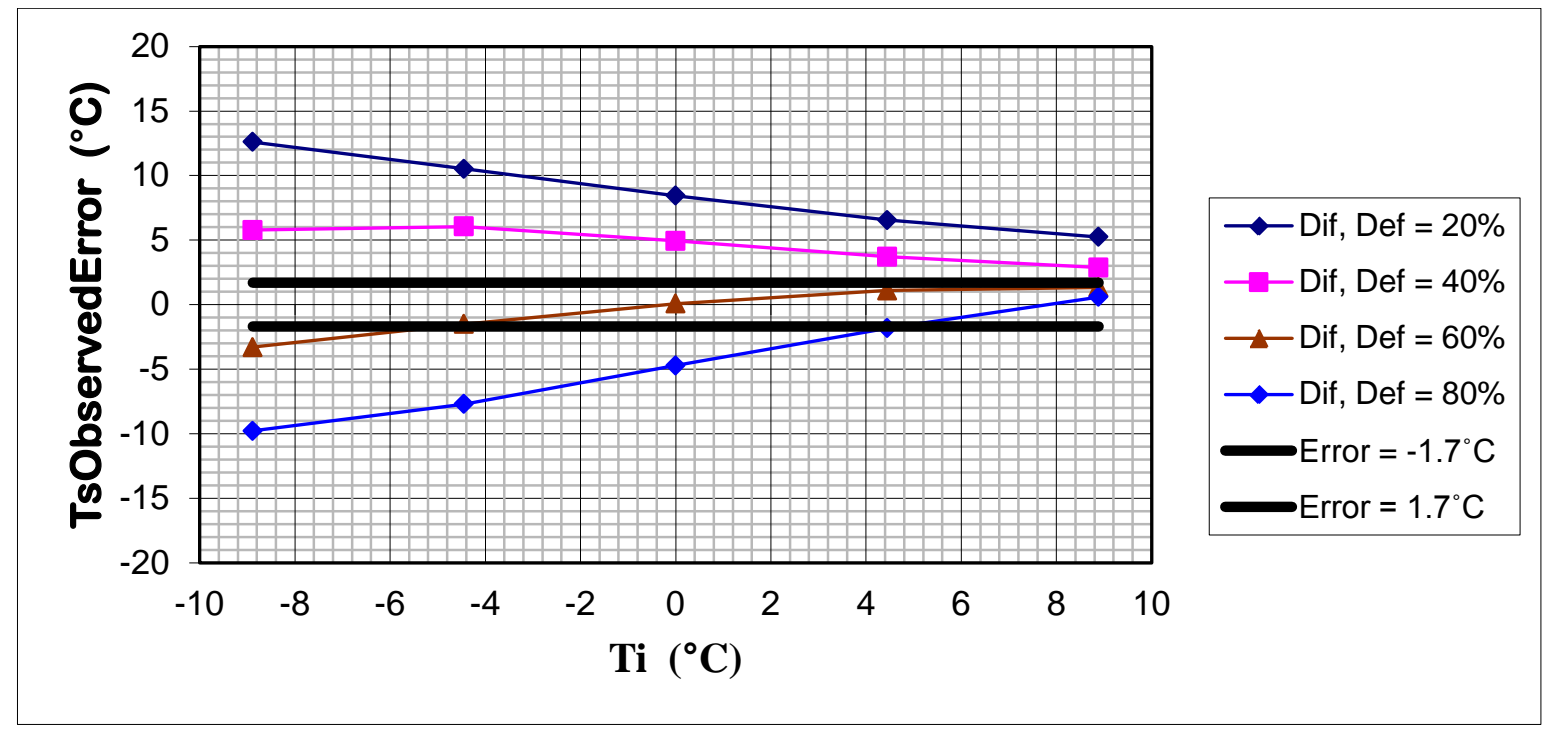

Figure 22. TsObservedError with both the inlet and exhaust dampers are stuck open 20\%, $40 \%, 60 \%$, and $80 \%$.

From Figures 20, 21, and 22, one may conclude that faults involving either the inlet air damper or the exhaust damper stuck open more than 50\% are not likely to be detected. However, most faults involving both the inlet and exhaust damper stuck open to the same degree are sooner or later likely to be detected due to the expected variation in Ti with outside temperature, with the possible exception when both dampers are stuck open around 60\%.

\section{COOLING COIL FAULT DETECTION RESULTS}

Faults involving the valve controlling the flow of chilled water through the cooling coil are easily detected because the supply air temperature will not be maintained at the supply air temperature setpoint. As discussed in the Introduction, this kind of fault is not the subject of this paper.

Faults involving errors in the chilled water temperature sensor, the supply air temperature sensor, and entering air temperature sensor, or fouling of the cooling coil are more difficult to detect. These faults result in chilled water mass flow rates that are different from what would occur if no faults were present. This error-induced chilled water mass flow rate can be used in the equation for TempAirOutAAA, which was discussed above, to predict a supply air temperature that differs from the supply air temperature setpoint. Difference between TempAirOurAAA and the supply air temperature setpoint 
equal to or greater than the $\pm 1.3{ }^{\circ} \mathrm{C}$ indicate the presence of a fault. The size of the minimum detectable sensor error is found by trial and error.

In a real AHU, the chilled water flow rate resulting from the fault must either be measured directly or calculated from the (measured) position of the cooling coil valve. In this paper, the chilled water mass flow rate resulting from the existence of a fault will be calculated using the equation for MFRchwA with the fault present.

\section{DETECTION OF FAULT IN CHILLED WATER TEMPERATURE SENSOR}

For a fault involving a positive error in the chilled water temperature sensor, the actual chilled water temperature will be lower than the sensor reading. When the calculated chilled water flow rate, MFRchwA, based upon this actual (correct) chilled water temperature is inserted into the equation for TempAirOutAAA along with the erroneous chilled water temperature, the predicted supply air temperature, Tao $=$ TempAirOutAAA, is found to lie above the supply air temperature setpoint. Figure 23 shows the results for Tchw $=3.4{ }^{\circ} \mathrm{C}$, plf $=1$, and a positive error in Tchw of $1.5^{\circ} \mathrm{C}$ for values of Tai equal to TaoSP $+5{ }^{\circ} \mathrm{C}, 24{ }^{\circ} \mathrm{C}$, and TaiMid, where TaiMid is half way between TaoSP $+5{ }^{\circ} \mathrm{C}$ and $24{ }^{\circ} \mathrm{C}$. Since the predicted supply air temperature for all three values of Tai lie on or above the line defined by TaoSP $+1.3{ }^{\circ} \mathrm{C}$, faults involving positive errors in the chilled water temperature sensor that are greater than $1.5{ }^{\circ} \mathrm{C}$ should be detectable. Additional analysis shows that positive errors greater than $1.5{ }^{\circ} \mathrm{C}$ should be detectable independent of changes in the values of Tchw or plf.

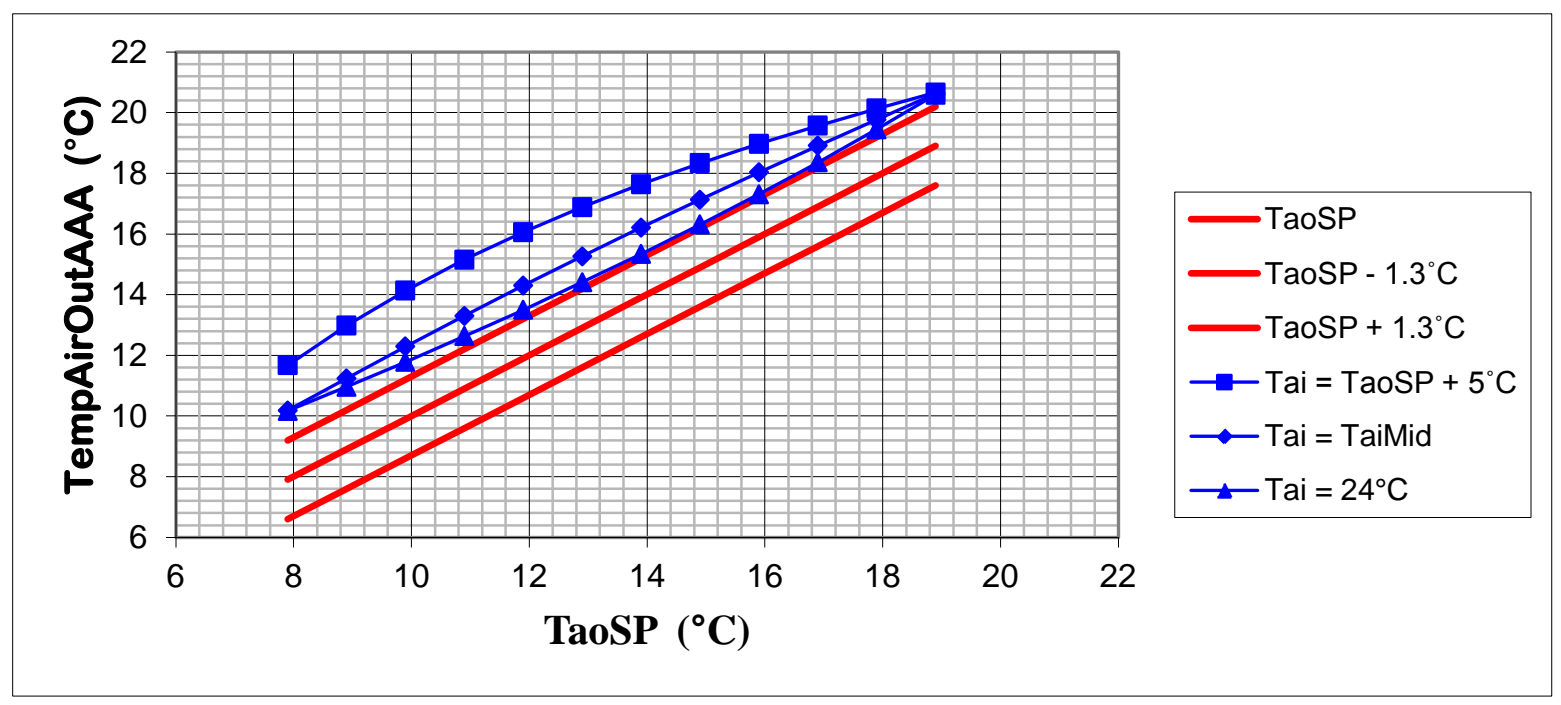

Figure 23. Predicted supply air temperature, Tao $=$ TempAirOutAAA, for a positive error in Tchw of $1.5{ }^{\circ} \mathrm{C}$ for values of Tai equal to TaoSP $+5^{\circ} \mathrm{C}$, TaoMid, and $24^{\circ} \mathrm{C}$.

For a fault involving a negative error in the chilled water temperature sensor, the actual chilled water temperature will be higher than the sensor reading. When the calculated chilled water flow rate, MFRchwA, based upon this actual (correct) chilled water temperature is inserted into the equation for TempAirOutAAA along with the erroneous chilled water temperature, the predicted supply air 
temperature, Tao $=$ TempAirOutAAA, is found to lie below the supply air temperature setpoint. Figure 24 shows the results for Tchw $=3.4{ }^{\circ} \mathrm{C}$, plf $=1$, and a negative error in Tchw of $1.5^{\circ} \mathrm{C}$ for values of Tai equal to TaoSP $+5{ }^{\circ} \mathrm{C}, 24{ }^{\circ} \mathrm{C}$, and TaiMid, where TaiMid is half way between TaoSP $+5{ }^{\circ} \mathrm{C}$ and $24{ }^{\circ} \mathrm{C}$. Since the predicted supply air temperature for all three values of Tai lie on or below the line defined by TaoSP $-1.3{ }^{\circ} \mathrm{C}$, faults involving negative errors in the chilled water temperature sensor that are greater than $1.5{ }^{\circ} \mathrm{C}$ should be detectable. Additional analysis shows that negative errors greater than $1.5{ }^{\circ} \mathrm{C}$ should be detectable, independent of changes in the values of Tchw or plf.

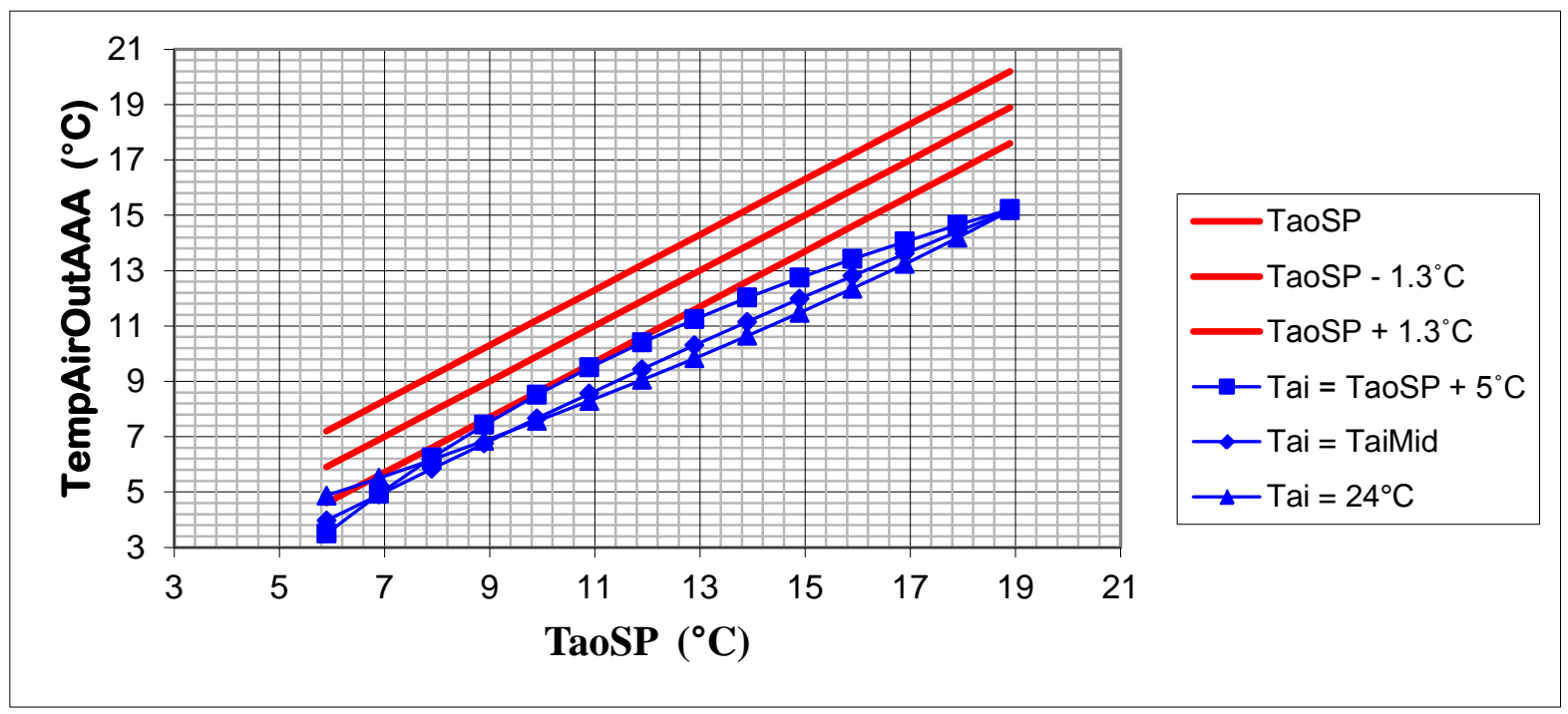

Figure 24. Predicted supply air temperature, Tao $=$ TempAirOutAAA, for a negative error in Tchw of $1.5^{\circ} \mathrm{C}$ for values of Tai equal to TaoSP $+5^{\circ} \mathrm{C}$, TaoMid, and $24^{\circ} \mathrm{C}$.

\section{DETECTION OF FAULT IN SUPPLY AIR TEMPERATURE SENSOR}

For a fault involving a positive error in the supply air temperature sensor, inserting the calculated chilled water flow rate, MFRchwA (based upon the actual (correct) leaving air temperature (TaoSP - error in supply air temperature sensor) into the equation for TempAirOutAAA, results in predicted supply air temperatures that lie below the supply air temperature setpoint. Figure 25 shows the results for Tchw $=$ $3.4^{\circ} \mathrm{C}$, plf $=1$, and a positive error in the supply air temperature sensor of $2.5^{\circ} \mathrm{C}$ for values of Tai equal to TaoMin, $24{ }^{\circ} \mathrm{C}$, and TaiMid, where TaiMin $=\left(\right.$ TaoSP - Error $\left.+5{ }^{\circ} \mathrm{C}\right)$ and TaiMid is half way between TaiMin and $24^{\circ} \mathrm{C}$. Since the predicted supply air temperature for all three values of Tai lie on or below the line defined by TaoSP $-1.3{ }^{\circ} \mathrm{C}$, faults involving positive errors in the supply air temperature sensor that are greater than $2.5^{\circ} \mathrm{C}$ should be detectable. Additional analysis shows that positive errors greater than $2.5^{\circ} \mathrm{C}$ should be detectable independent of changes in the values of Tchw or plf. 


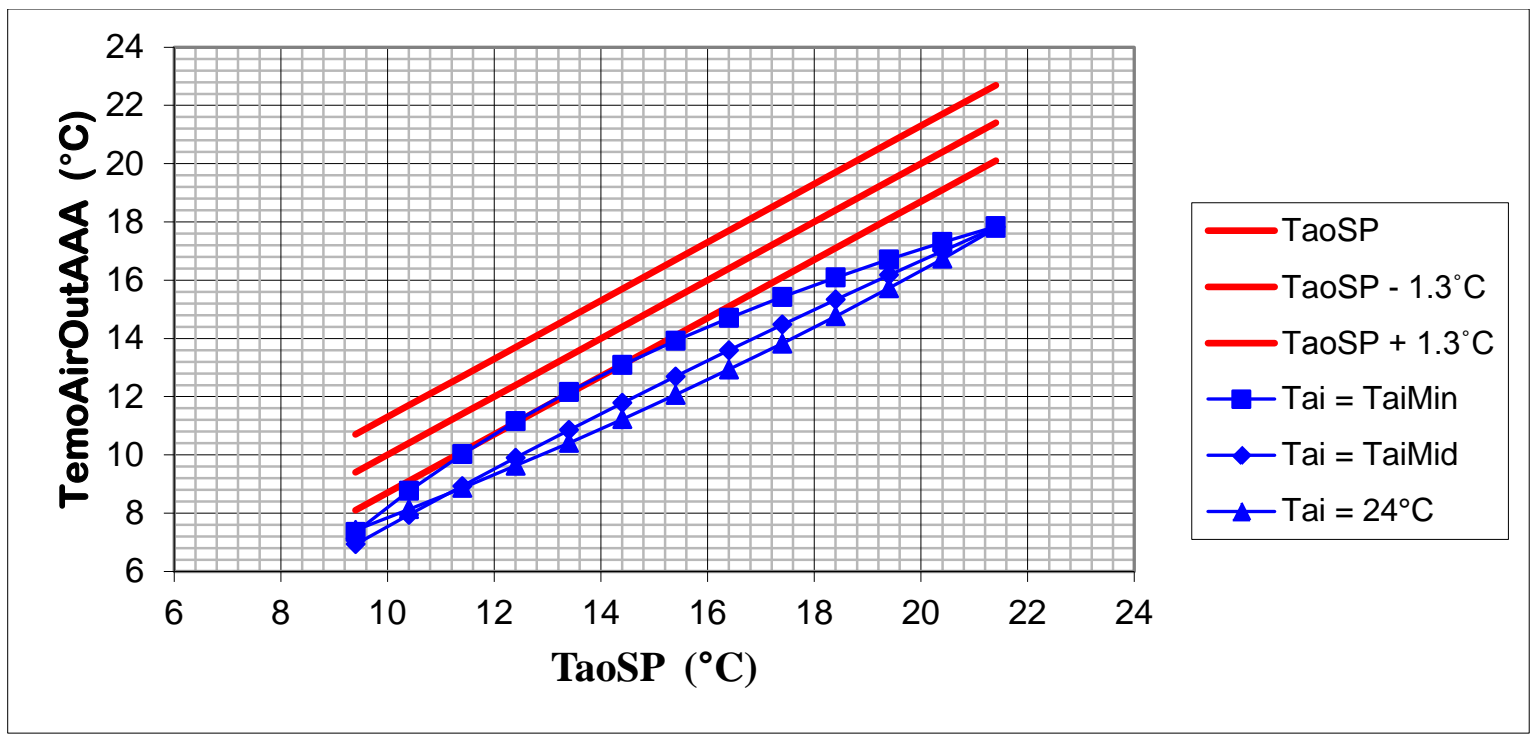

Figure 25. Predicted supply air temperature, Tao $=$ TempAirOutAAA, for a positive error in the supply air temperature sensor of $2.5{ }^{\circ} \mathrm{C}$ for values of Tai equal to TaoSP + $5^{\circ} \mathrm{C}$, TaoMid, and $24^{\circ} \mathrm{C}$.

For a fault involving a negative error in supply air temperature sensor, inserting the calculated chilled water flow rate, MFRchwA (based upon the actual (correct) leaving air temperature (TaoSP - error in supply air temperature sensor), into the equation for TempAirOutAAA, results in predicted supply air temperatures that lie above the supply air temperature setpoint. Figure 26 shows the results for Tchw = $3.4{ }^{\circ} \mathrm{C}$, plf $=1$, and a negative error in the supply air temperature sensor of $2.5^{\circ} \mathrm{C}$ for values of Tai equal to TaoMin, $24{ }^{\circ} \mathrm{C}$, and TaiMid, where TaiMin $=\left(\right.$ TaoSP - Error $\left.+5{ }^{\circ} \mathrm{C}\right)$ and TaiMid is half way between TaiMin and $24{ }^{\circ} \mathrm{C}$. Since the predicted supply air temperature for all three values of Tai lie on or above the line defined by TaoSP $+1.3{ }^{\circ} \mathrm{C}$, faults involving negative errors in the supply air temperature sensor that are greater than $2.5^{\circ} \mathrm{C}$ should be detectable. Additional analysis shows that negative errors greater than $2.5^{\circ} \mathrm{C}$ should be detectable independent of changes in the values of Tchw or plf. 


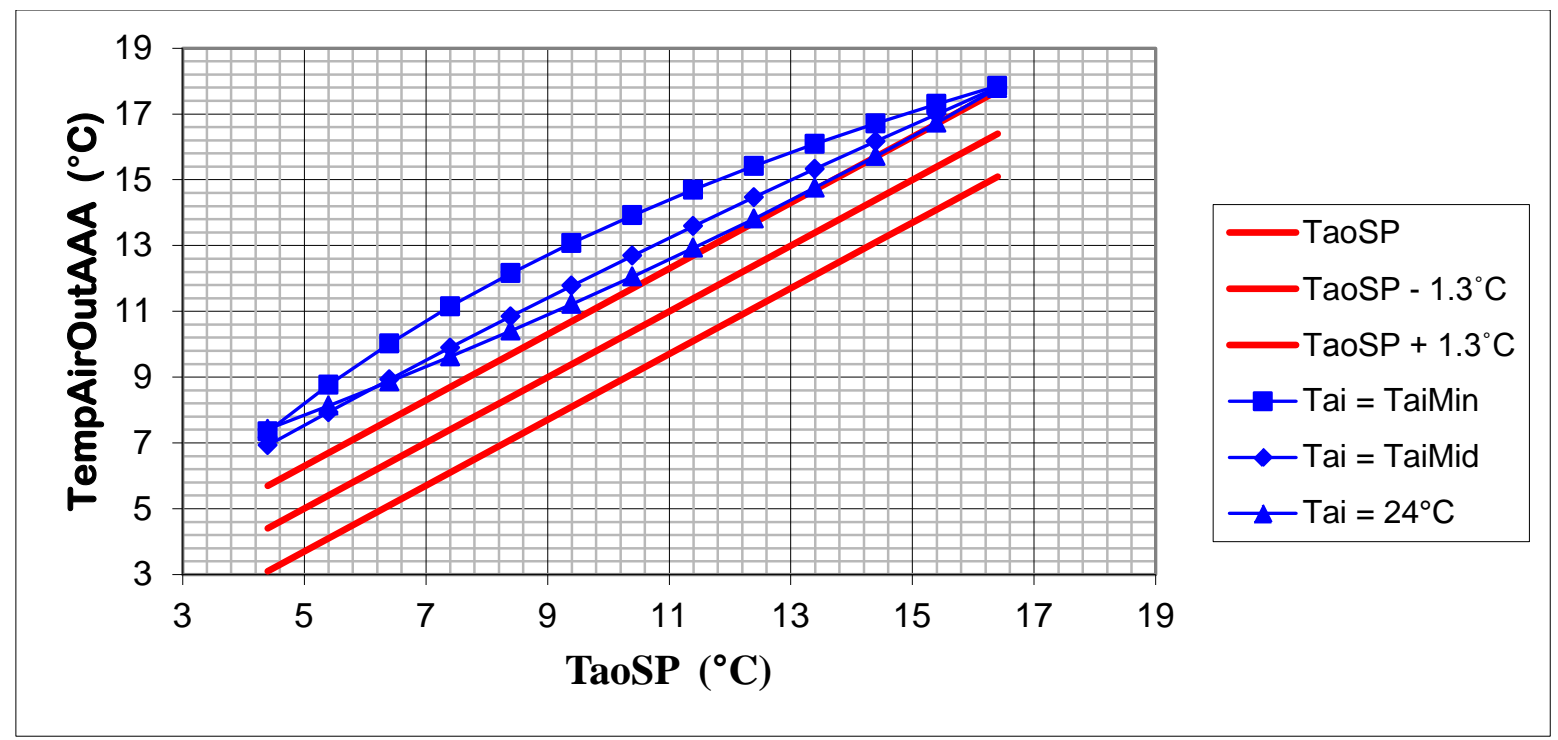

Figure 26. Predicted supply air temperature, Tao $=$ TempAirOutAAA, for a negative error in the supply air temperature sensor of $2.5{ }^{\circ} \mathrm{C}$ for values of Tai equal to TaoSP + $5^{\circ} \mathrm{C}$, TaoMid, and $24^{\circ} \mathrm{C}$.

\section{FAULT IN ENTERING AIR TEMPERATURE SENSOR}

Figures 27 and 28 show the predicted value of Tao $=$ TempAirOutAAA for an Error of $+4{ }^{\circ} \mathrm{C}$ and a $-4{ }^{\circ} \mathrm{C}$, respectively, in the entering air temperature sensor, Tai, for a chilled water temperature of $3.34{ }^{\circ} \mathrm{C}$ and a plf $=1$. In both figures, TaiMin $=$ Tao $+5{ }^{\circ} \mathrm{C}+$ Error, TaiMax $=24{ }^{\circ} \mathrm{C}+$ Error, and TaiMid lies half way between TaiMin and TaiMax. These three values (TaiMin, TaiMid, and TaiMax) all correspond to the incorrect readings given by the faulty entering air temperature sensor. Larger errors in Tai, higher chilled water temperatures, and smaller values of plf all produce curves that lie further away from the region bounded by the lines TaoSP $+1.3{ }^{\circ} \mathrm{C}$ and TaoSP $-1.3{ }^{\circ} \mathrm{C}$.

From Figure 27, we see that when TaoSP is greater than $9^{\circ} \mathrm{C}$, the predicted supply temperature for all three values of Tai lie on or below the line defined by TaoSP $-1.3^{\circ} \mathrm{C}$. Thus faults involving positive errors greater than $4^{\circ} \mathrm{C}$ in the supply air temperature sensor should be detectable when TaoSP $\geq 9^{\circ} \mathrm{C}$. Similarly, from Figure 28, we find that the predicted supply air temperature for all three values of Tai lie above the line defined by TaoSP $+1.3{ }^{\circ} \mathrm{C}$, faults involving negative errors equal to or greater than $4{ }^{\circ} \mathrm{C}$ in the supply air temperature sensor should be detectable for all reasonable values of Tao. Additional analysis shows that these conclusions are unaffected by changes in the values of Tchw or plf. 


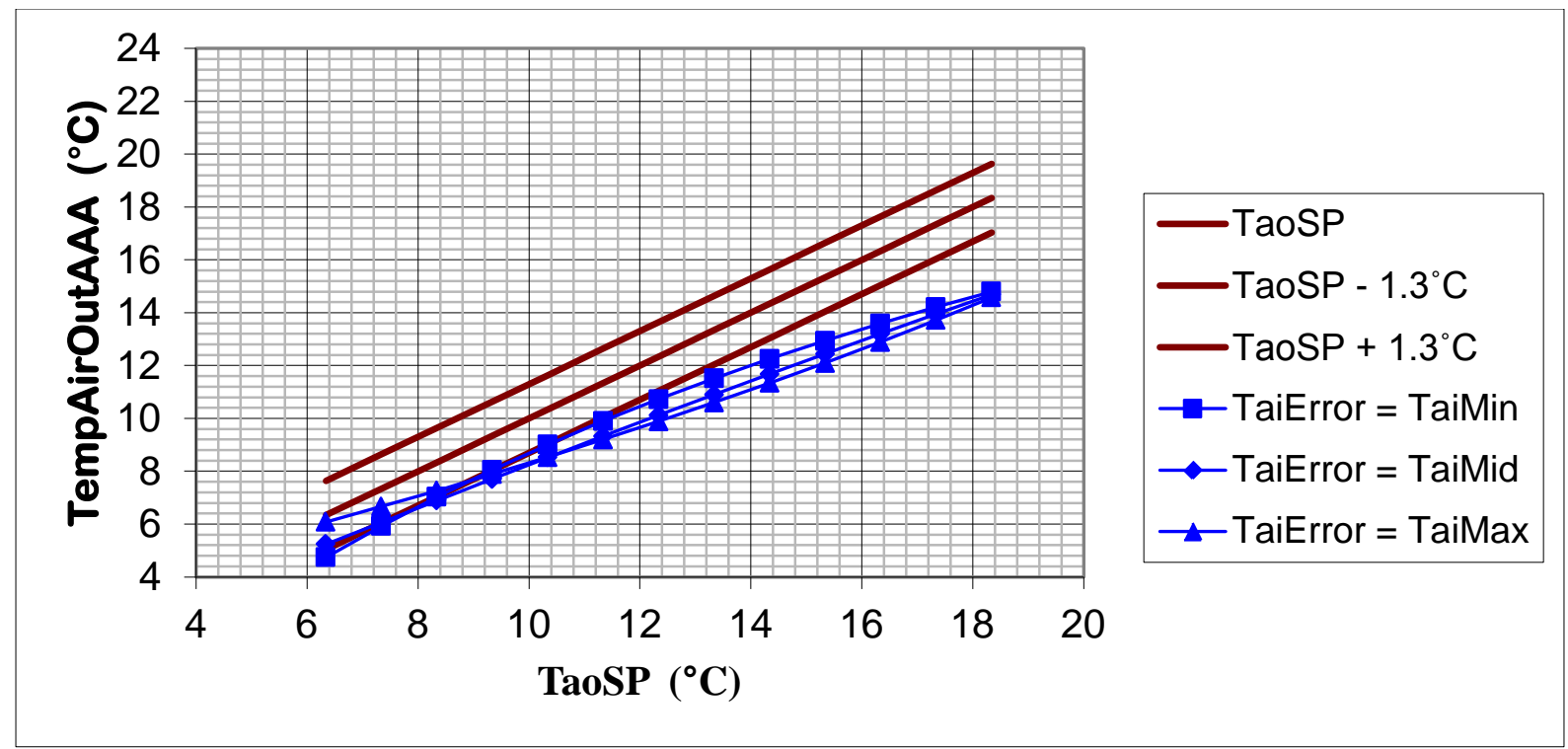

Figure 27. Predicted value of Tao $=$ TempAirOutAAA for a positive error of $4{ }^{\circ} \mathrm{C}$ in the entering air temperature sensor, Tai, a chilled water temperature of $3.34{ }^{\circ} \mathrm{C}$, and plf $=1$.

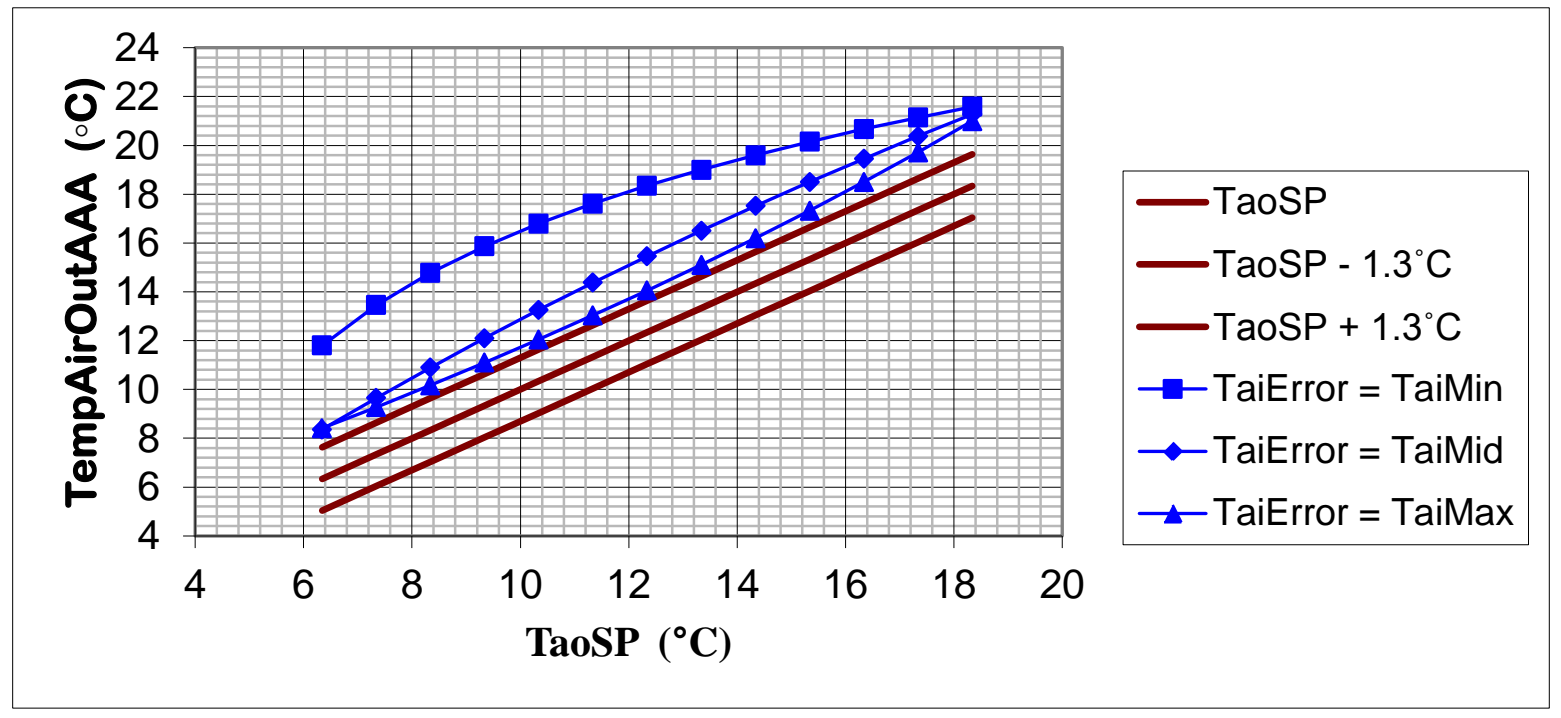

Figure 28. Predicted value of Tao $=$ TempAirOutAAA for a negative error of $4{ }^{\circ} \mathrm{C}$ in the entering air temperature sensor, Tai, a chilled water temperature of $3.34{ }^{\circ} \mathrm{C}$, and plf $=1$.

\section{FOULING OF COOLING COIL FAULT}

Fouling, whether on the air side or water side of a cooling coil, decreases the cooling capacity of the coil. Introducing a fouling factor, FF, (Zhao 2011) that decreases the cooling capacity of the coil gives the following equations. 
$\operatorname{rateSA}($ plf, Tai, Tao $)=\frac{\text { plf } \cdot \text { Qmax }}{(1.0 \cdot(\text { Tai }- \text { Tao }))}$

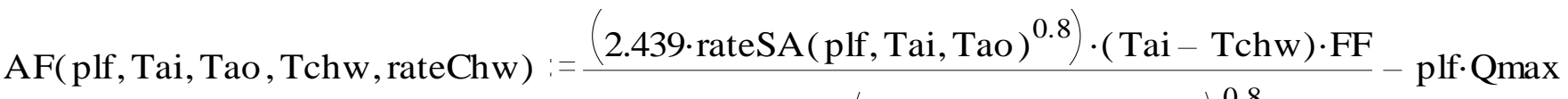
$1+0.498 \cdot\left(\frac{\text { rateSA }(\mathrm{plf}, \mathrm{Tai}, \mathrm{Tao})}{\text { rateChw }}\right)^{0.8}$

MFRchwF(plf, Tai, Tao, Tchw) = root(AF(plf, Tai, Tao, Tchw, rateChw), rateChw)

The results are shown in Figure 29 for $\mathrm{FF}=0.85$ with Tchw $=3.33{ }^{\circ} \mathrm{C}$ and plf $=1$, where TaiMin $=$ TaoSP $+5{ }^{\circ} \mathrm{C}$, TaiMax $=24{ }^{\circ} \mathrm{C}$, and TaiMid is half way between TaiMin and TaiMax. Since all three curves for Tai lie below the line defined by TaoSP $-1.3{ }^{\circ} \mathrm{C}$, faults involving either water or air side fouling that decrease the coil capacity by more than $15 \%$ should be detectable.

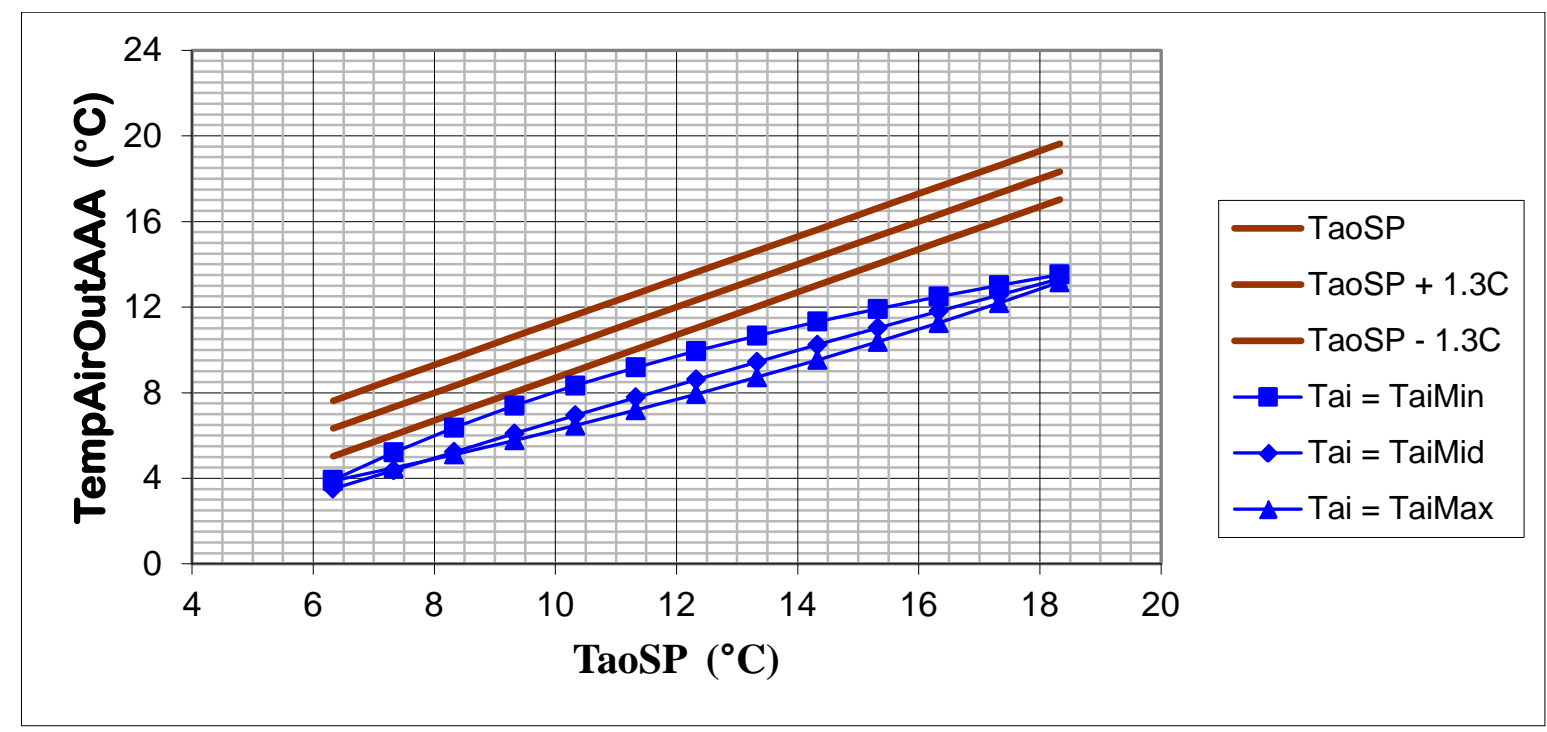

Figure 29. Predicted value of Tao = TempAirOutAAA for water or air side fouling that reduces the capacity of the cooling coil by $15 \%$; Tchw and plf equal $3.33{ }^{\circ} \mathrm{C}$ and 1 , respectively.

\section{SUMMARY AND RECOMMENDATIONS}

It has been shown that many faults in building air handling units involving closed loop control could be detected if an accurate model of normal operation either exists or can be developed by monitoring the system's performance when no faults are present. The latter approach is called on-line system identification and can be readily carried out using intelligent agents. 
The detection of a particular fault also depends upon the nature of the fault (e.g., where the fault is located), the limitations of the identified system model, and the size of the fault. Understanding which faults are likely to be detectable and under what conditions is important to the successful implementation of any fault detection method in a real building HVAC system.

Simple models of an AHU mixing box and a cooling coil were presented. Piece-wise linear approximations to represent what might be obtained by on-line system identification using linear regression and, in the case of the cooling coil, additional approximations to reduce the number of variables involved, were then employed to obtain simplified models representative of those that might be developed by intelligent agents using on-line system identification techniques. These simplified models were then used to study likely faults in the closed loop control of AHU mixing boxes and cooling coils that should be detectable and under what conditions.

For mixing boxes it was found that the detection of a stuck recirculation air damper depended on the position of the stuck damper, the supply air temperature, and the entering air temperature. It was concluded, however, that because the entering air temperature varies with the outdoor temperature over such a wide range, a recirculation air damper stuck at almost any position would likely be detected sooner or later.

The detection of a stuck inlet air damper or a stuck exhaust air damper was more difficult. It was determined that these faults were only likely to be detected if the damper was stuck at a position less than $50 \%$ open. However, if both the inlet and exhaust air dampers were both stuck open to the same degree, then sooner or later this type of fault would likely be detected, with the exception of when both dampers are stuck around $60 \%$ open.

For the cooling coil it was found that positive and negative errors greater than $1.5^{\circ} \mathrm{C}$ in the chilled water temperature sensor were likely to be detected. Similarly, positive and negative errors greater than $2.5^{\circ} \mathrm{C}$ in the supply air temperature sensor should be detectable. Positive errors greater than $4{ }^{\circ} \mathrm{C}$ in the entering air temperature sensor are detectable when the supply air temperature, Tao, is $\geq 9{ }^{\circ} \mathrm{C}$, while negative errors $\geq 4{ }^{\circ} \mathrm{C}$ are detectable for all reasonable values of Tao. An examination of cooling coil fouling showed that fouling (either on the water side or air side) that resulted in the cooling capacity being reduced by $15 \%$ or more was likely to be detected.

While not all the faults likely to occur in the closed loop control of AHU mixing boxes and cooling coils can be detected by the method described in this paper, many can. The approach described in this paper is worthy of being implemented in real building systems using intelligent agents. However, the authors believe that there is little to be gained by studying these fault detecting intelligent agents in a simulation environment. Rather, it is recommended that, as a next step, intelligent agents implementing this fault detection method be developed and tested in a laboratory setting where faults of various kinds and magnitudes can be easily introduced and studied without affecting the comfort of building occupants.

\section{REFERENCES}

Hyvärinen, J., Kärki, S., 1996. IEA Annex 25 Building Optimization and Fault Diagnosis Source Book, Technical Research Centre of Finland, VTT Building Technology, FIN-02044 VTT (Espoo) 
Katipamula, S., Brambley, M. R., 2005 Part I. Methods for Fault Detection, Diagnostics, and Prognostics for Building Systems - A Review, Part I, HVAC\&R Research, Vol. 11, No. 1, January 2005.

Katipamula, S., Brambley, M. R., 2005 Part II. Methods for Fault Detection, Diagnostics, and Prognostics for Building Systems - A Review, Part II, HVAC\&R Research, Vol. 11, No. 2, April 2005.

Kelly, G. E., Bushby, S. T., 2011. Optimization of Building HVAC Systems Using Intelligent Agents A Proof of Concept Study. NIST TN 1707.

Kelly, G. E., Bushby, S. T,. 2012. Are intelligent agents the key to optimizing building HVAC system performance? HVAC\&R Research, Vol 18, Issue 4, 750-759, 2012.

Legg, R. C., 1986. Characteristics of single and multi-blade dampers for ducted air systems. Building Services Engineering Research and Technology, 7(4)

Ljung, L., 1987. System Identification Theory for the User, Prentice-Hall, Inc., Englewood Cliffs, NJ.

Schein, J., Bushby, S. T., Castro, N. S., House, J. M., 2006. A rule-based fault detection method for air handling units. Energy and Buildings, Vol 38, Issue 12, 1485-1492, December 2006.

Seem, J. E., House, J. M., Klaassen, C. J., 2000. A damper control system for preventing reverse airflow through the exhaust air damper of variable-air-volume air-handling units. HVAC\&R Research, Vol. 6, No. 2, 135-148, April 2000.

Tan, H., Dexter, A., 2006. Estimating airflow rates in air-handling units from actuator control signals. Building and Environment. Vol. 41, Issue 10, 1291-1298, October 2006.

Wang, Y., Cai, W., et al. 2004. A simplified modeling of cooling coils for control and optimization of HVAC systems. Energy Conversion and Management 45, p. 2915-2930.

Wang, S. W., Zhou, Q., Xiao, F., 2010. A system-level fault detection and diagnosis strategy for HVAC systems involving sensor faults, Energy and Buildings. 42(4), 477-490, April 2010.

Zhao, L., Cai, W., Ding, X., 2011. A Modified Hybrid Model of Heat Exchanger Based on Fouling Effect, $6^{\text {th }}$ IEEE Conference on Industrial Electronics and Applications, 2011. 


\section{TERMINOLOGY KEY}

\section{Mixing Box Terminology}

$\mathrm{x}-\quad$ position of inlet and exhaust dampers $(0=$ closed, $1=$ open $)$

$(1-\mathrm{x})-$ position of recirculating and exhaust dampers $(0=$ closed, $1=$ open $)$

P0 - $\quad$ atmospheric pressure

$\mathrm{P} 1(\mathrm{x})$ - pressure at the junction of the return air duct and recirculating air duct

$\mathrm{P} 2(\mathrm{x})$ - pressure at the junction of the recirculating air duct and the supply air duct

Qs - $\quad$ supply air flow rate

Qr - return air flow rate

$\mathrm{Qe}(\mathrm{x})$ - exhaust air flow rate

$\mathrm{Qx}(\mathrm{x})$ - recirculating air flow rate

$\mathrm{Qi}(\mathrm{x})$ - inlet air flow rate

$\operatorname{Tx}(\mathrm{x})$ - temperature of the recirculating air

Ts $(\mathrm{x})$ - temperature of the supply air

$\mathrm{Te}-\quad$ temperature of the exhaust air

$\mathrm{Tr}-\quad$ temperature of the Return Air

$\mathrm{Ti}-\quad$ temperature of the Inlet Air

$\mathrm{Ri}(\mathrm{x})$ - inlet air damper resistance

$\operatorname{Re}(\mathrm{x})$ - exhaust air damper resistance

$\mathrm{Rx}(\mathrm{x})$ - recirculating air damper resistance

$\mathrm{Ai}-\quad$ authority of the inlet damper

Ae - authority of the exhaust damper

Ax - authority of the recirculation damper

ratioQiToQs(x) - $\quad$ ratio of inlet air flow rate to supply air flow rate without any faults present

ratioQxToQs(x) - $\quad$ ratio of recirculating air flow rate to supply air flow rate without any faults present

ratioQeToQs(x) - $\quad$ ratio of exhaust air flow rate to supply air flow rate without any faults present

ratiofQiToQs(x) - $\quad$ ratio of inlet air flow rate to supply air flow rate with damper faults present

ratiofQxToQs(x) - $\quad$ ratio of recirculating air flow rate to supply air flow rate with damper fault present

ratiofQeToQs(x) - ratio of exhaust air flow rate to supply air flow rate with damper fault present

ESTratioQiToQs(x) - calculated ratio of inlet air flow rate to supply air flow rate using linearized mixing box model without any faults present

ESTratioQxToQs $(x)$ - calculated ratio of recirculating air flow rate to supply air flow rate using linearized mixing box model without any faults present

ESTratioQeToQs(x) - calculated ratio of exhaust air flow rate to supply air flow rate using linearized mixing box model without any faults present 
ESTTs(x, Ti) - $\quad$ calculated supply air temperature using the linear approximation of the real model

Tsf(x, Ti) - calculated supply air temperature using full mixing box model with faults present

TaSP - temperature setpoint of air leaving mixing box

$\mathrm{y}-\quad$ value of $\mathrm{x}$ at which $\operatorname{Tsf}(\mathrm{x}, \mathrm{Ti})$ equals TaSP

TsPredicted(y) - $\quad$ calculated supply air temperature using linearized mixing box model without any faults present

TsObservedError - observed error in supply air temperature equal to the difference between Tsf(x, Ti) and TsPredicted(y)

Dxf - recirculating damper fault equal to the percent the damper is stuck open

Dif - inlet damper fault equal to the percent the damper is stuck open

Def - exhaust damper fault equal to the percent the damper is stuck open

\section{Cooling Coil Termonology}

Q - $\quad$ cooling coil capacity

Qmax - maximum cooling coil capacity

plf - $\quad$ part load factor (Q/Qmax)

Tai - $\quad$ entering air wet bulb temperature for a wet coil, entering air dry bulb temperature for a dry coil

Tao - temperature or air leaving cooling coil, equals supply air temperature, Ts

Tchw - temperature of chilled water entering cooling coil

Two - temperature of water leaving cooling coil

rateSA - supply air flow rate

rateChw - chilled water flow rate

mchwDesign - maximum water flow rate that the cooling coil was designed to handle under normal conditions

TaoSP - temperature setpoint of air leaving cooling coil (i.e., the supply air temperature setpoint)

MFRchwA -

TempAirOutA -

MFRchwAA -

MFRchwF -

TempAirOutAA -

TempAirOutAAA - calculated value of the chilled water mass flow rate through the cooling coil using the full cooling coil model developed by Wang (Wang 2004)

calculated value of the temperature of the air leaving the cooling coil using the full cooling coil model developed by Wang (Wang 2004)

calculated value of the chilled water mass flow rate through the cooling coil using the water side effectiveness model

calculated value of the chilled water mass flow rate through the cooling coil using the fouled cooling coil model

calculated value of the temperature of the air leaving the cooling coil using the water side effectiveness model

calculated value of the temperature of the air leaving the cooling coil using the linearized water side effectiveness model 
$\mathrm{EFFw}-$

EFFWEST -

FF - water side effectiveness model derived from the full cooling coil model developed by Wang (Wang 2004)

linearized version of the water side effectiveness model, EFFw

fouling factor 